\title{
5. Spielarten internationaler Rezeptivität in der Wiener Moderne
}

Während in Deutschland noch im Erscheinungsjahr der ersten Übersetzungen von Turgenevs Stichotvorenija ע proze das neue Gattungsmodell aufgegriffen wurde, verging in Österreich ein ganzes Jahrzehnt, bis es zur Abfassung von Prosagedichten kam. Diese merkwürdige zeitliche Verschiebung resultiert nicht etwa - wie man vielleicht vermuten könnte - aus einer nur schwachen Turgenev-Rezeption im Nachbarland, ${ }^{1}$ sondern hängt vielmehr mit charakteristischen Unterschieden im Literatursystem beider Nationen zusammen. ${ }^{2}$ So war es in der Donaumonarchie nicht zu einer wirklichen „Emancipation« der Erzählprosa gekommen, ${ }^{3}$ weil das Drama und die Lyrik in der akademischen Poetik ebenso wie in der literarischen Produktion der zeitgenössischen Autoren ihre Vormachtstellung behaupten konnten. Die damit verbundene Persistenz einer kklassischen, den Prämissen des Idealismus verpflichteten Gattungshierarchie wiederum hatte erheblich dazu beigetragen, daß sich das Realismusparadigma in der Ästhetik kaum - und wenn, dann nur ansatzweise - durchzusetzen vermochte. Eine mit den übrigen europäischen Nationalliteraturen vergleichbare naturalistische Bewegung schließlich blieb in Österreich fast gänzlich aus. ${ }^{4}$ Kurz gesagt: Es bestand dort geraume Zeit kein spezifisches 'Bedürfnisı nach An-

1 Vgl. hierzu Günther Wytrzens: Zur österreichischen Turgenev-Rezeption bis 1918. In: Wiener Slavistisches Jahrbuch 28 (1982), S. 107-126.

2 Die darauf einwirkenden sozial- und mentalitätsgeschichtlichen Aspekte untersucht ausführlich Eike Middell: Literatur zweier Kaiserreiche. Deutsche und österreichische Literatur der Jahrhundertwende.

3 Żmegač spricht in diesem Zusammenhang von der wzumindest partiellen Traditionslosigkeit [...] im Hinblick auf den Roman«; Viktor Żmegač: Die Wiener Modeme und die Tradition literarischer Gattungen. In: Hofmannsthal-Jahrbuch zur europäischen Moderne 5 (1997), S. 215. Daß sich diese Gattung im Österreich des 19. Jahrhunderts anders als in den meisten anderen europäischen Literaturen nur mit Verzögerung durchsetzen konnte, ist bekannt; vgl. hierzu die kürzlich erschienene Studie von Primus-Heinz Kucher. Ungleichzeitige/verspätete Moderne. Prosaformen in der österreichischen Literatur 1820-1870. Tübingen/Basel: Francke 2001. Nach Żmegač war die Frontstellung "gegen eine extensiv-mimetische Auffassung von Literaturu der Hauptgrund für das "gebrochene oder zumindest [...] belastete Verhältnis« der österreichischen Autoren zu allen narrativen Langformen; Viktor Żmegač: Die Wiener Modeme und die Tradition literarischer Gattungen, S. 206 und 216.

In pointierter Zuspitzung stellt bereits Friedell fest: "Auf österreichischem Boden hat es 
eignung des Prosagedichts. Dies änderte sich erst, als zu Beginn der neunziger Jahre der Import französischer Kunstkonzepte ${ }^{5}$ das Augenmerk der Kulturproduzenten verstärkt auf das Genre lenkte. Doch mittlerweile hatte sich die Rezeptionsgrundlage aufgefächert: Im Unterschied zu ihren deutschen Kollegen lernten die österreichischen Autoren das neuartige Gattungsmodell bereits in divergierenden Spielarten kennen, was ihnen natürlich eine Vielzahl von inhaltlichen, formalen und sprachlichen Optionen eröffnete. Zudem ereigneten sich Rezeption und Indienstnahme der Textform Prosagedicht im Rahmen der Wiener Moderne ${ }^{6}$ dezidiert im Kontext antinaturalistischer Strömungen. ${ }^{7}$ Die eigentümliche kulturelle Verspätung ${ }^{8}$ Österreichs schlug auf diese Weise mit einem Mal in eine künstlerische Avantgardeposition um.

überhaupt keinen Naturalismus gegeben." Egon Friedell: Kulturgeschichte der Neuzeit. Die Krisis der europäischen Seele von der schwarzen Pest bis zum Ersten Weltkrieg [192731]. München: C.H. Beck 1989 (= Beck'sche Sonderausgaben), S. 1455.

5 Dies hängt mit der ausgeprägten internationalen Rezeptivität der Wiener Moderne zusammen, die u.a. durch die Institution des Kaffeehauses entscheidend befördert wurde. Zweig etwa schreibt in seinen Erinnerungen: "So wußten wir alles, was in der Welt vorging, aus erster Hand, wir erfuhren von jedem Buch, das erschien, von jeder Aufführung, wo immer sie stattfand, und verglichen in allen Zeitungen die Kritiken; nichts hat vielleicht so viel zur intellektuellen Beweglichkeit und intemationalen Orientierung des Österreichers beigetragen, als daß er im Kaffeehaus sich über alle Vorgänge der Welt so umfassend orientieren und sie zugleich im freundschaftlichen Kreis diskutieren konnte. Täglich saßen wir dort stundenlang, und nichts entging uns." Stefan Zweig. Die Welt von Gestern. Erinnenungen eines Europäers. Frankfurt a.M.: S. Fischer 1993, S. 56f. Vgl. in diesem Zusammenhang auch Wolfgang Bunzel: Kaffeehaus und Literatur in Wien um 1900. In: Hansers Sozialgeschichte der deutschen Literatur vom 16. Jahrhundert bis zur Gegenwart, Bd. 7, S. 287 $299,622-627$.

6 Ausgeklammert werden hier Schriftsteller, die entweder gruppensoziologisch oder aus chronologischen Gründen außerhalb eines weit verstandenen Kreises Jung-Wienc anzusiedeln sind. Zu nennen wären hier etwa Franz Himmelbauer und Stefan Zweig.

7 Zur Baudelaire-Rezeption der jungen österreichischen Autoren vgl. Wendelin SchmidtDengler: Französischer Symbolismus und Wiener Dekadenz. In: From Vormärz to Fin de Siècle. Essays in Nineteenth Century Austrian Literature. Ed. by Mark G. Ward. Blairgowrie: Lochee Publications 1986, S. 73-89.

8 Vgl. hierzu etwa William M. Johnston: Österreichische Kultur- und Geistesgeschichte 1848-1918. Gesellschaft und Ideen im Donauraum 1848 bis 1938 [1972]. Wien/Köln: Böhlau 1974 (= Forschungen zur Geschichte des Donauraumes 1), und Carl E. Schorske: Wien. Geist und Gesellschaft im Fin de siècle [1979]. Frankfurt a.M.: S. Fischer 1982.

9 Le Rider konstatiert zutreffend meinen Verspätungseffekt, der sich dann mit einer ebenso ausgeprägten Modernisienung verbindet, durch die der Rückstand nahezu aufgeholt wirdı; Jacques Le Rider: Das Ende der Illusion. Die Wiener Modeme und die Krisen der Identität. Aus dem Französischen übersetzt von Robert Fleck. Wien: Österreichischer Bundesverlag 1990, S. 16. Im Hinblick auf die Literatur zeigt sich diese eigentümliche Dynamik vor allem daran, daß die Verbreitung und Aufnahme symbolistischer und ästhetizistischer Literaturkonzepte in Österreich - im Gegensatz zu Deutschland - sehr viel rascher und umfassender erfolgt. Vgl. hierzu generell Manfred Gsteiger: Französische Symbolisten in der deutschen Literatur der Jahrhundertwende (1869-1914). Bem/München: Francke 1971. 


\section{a. Bezugspunkt ästhetischer Selbstverortung:} Hugo von Hofmannsthals Prosagedichtentwürfe

Geradezu beispielhaft läßt sich die wechselnde Orientierung an verschiedenen Genremustern, die schließlich auch zu eigenen Schreibversuchen führt, bei Hugo von Hofmannsthal (1874-1929) beobachten. ${ }^{10}$ Der junge Autor wurde mit der Gattung zum ersten Mal konfrontiert, als er im Sommer 1890 Turgenevs Kurzprosa kennenlernte. Nach der Lektüre dieser Texte bemerkt er am 5. Juli in seinem Tagebuch:

Die Gedichte in Prosa, reine Lyrik, lose Gedanken, kleine Bilder, Allegorien. Ein Schimmer von Subjektivität über allem Das Aufgreifen des Alltäglichen, die meisterhaften kleinen Naturskizzen erinnem an die Spätromantiker, die Stimmung von Eichendorff. Heine, Helmer etwas variert. (H-GW X, S. 314)

Bei der Einschätzung des Gelesenen orientiert sich Hofmannsthal erkennbar an den vom Übersetzer der Vorlage paratextuell mitgelieferten Deutungsangeboten. Christoph Perels hat zeigen können, daß die Charakterisierung der turgenjevschen Texte als wreine Lyrik, lose Gedanken, kleine Bilder, Allegorien« unmittelbar auf die Vorrede jener Ausgabe bezogen ist, in der Hofmannsthal die Gedichte in Prosa mit größter Wahrscheinlichkeit gelesen hat: die 1883 in Breslau im Verlag von Eduard Trewendt erschienene deutsche Übersetzung von Raphael Löwenfeld nämlich. ${ }^{11}$ Löwenfeld seinerseits zitiert im Vorwort aus den einleitenden Bemerkungen, welche die Petersburger Zeitschrift Vestnik Europy (Europäischer Bote) in der russischen Erstveröffentlichung den Texten vorangeschickt hat. Dort werden die Prosagedichte u.a. als "flüchtige Aufzeichnungen, Gedanken, Bilder» bezeichnet; der Übersetzer fügt dem noch die Bezeichnungen »lyrische Stimmungsbilder, satyrische Allegorien ${ }^{12}$ hinzu und komplettiert damit das Bündel von Begriffen, das dann in geringfügig modifizierter Form in Hofmannsthals Tagebuch wiederkehrt.

10 Vgl. hierzu Wolfgang Bunzel: „Ungeheuer wenig überflüssigesw. Das Prosagedicht im kulturellen Kontext der Wiener Moderne. In: Zeitenwende - Die Germanistik auf dem Weg vom 20. ins 21. Jahrhundert. Akten des X. Intemationalen Germanistenkongresses Wien 2000. Hrsg. von Peter Wiesinger unter Mitarbeit von Hans Derkits. Bd. 6: Epochenbegriffe: Grenzen und Möglichkeiten. Betreut von Uwe Japp, Ryozo Maeda und Helmut Pfotenhauer. / Aufklärung - Klassik - Romantik. Betreut von John A. McCarthy, Albert Berger und Friedrich Vollhardt. / Die Wiener Modeme. Betreut von Marijan Bobinac und Wendelin Schmidt-Dengler. Bern/Berlin/Frankfurt a.M./New York/Oxford/Wien: Lang 2002 (= Jahrbuch für Internationale Germanistik. Reihe A: Kongreßberichte 58), S. 389-396.

11 Siehe Christoph Perels: Gedichte in Prosa von Ivan Turgenev - gelesen vom jungen Hofmannsthal. In: Zwiesprache. Beiträge zur Theorie und Geschichte des Übersetzens, hrsg. von Ulrich Stadler. In Zusammenarbeit mit John E. Jackson, Gerhard Kurz und Peter Horst Neumann. Stuttgart/Weimar: Metzler 1996, S. 123-125.

12 Iwan Turgeniew: Gedichte in Prosa. Mit Autorisation des Verfassers übersetzt von R.[aphael] Löwenfeld, S. VI und V. 
Freilich greift Hofmannsthal offensichtlich nur solche Charakterisierungen auf, die seinen ästhetischen Grundvorstellungen entsprechen. ${ }^{13}$ An diese - geborgten Kernelemente lagert er dann eigene Beobachtungen an mit dem Effekt, daß die Paraphrase durch den subjektiven Bewertungsrahmen erhebliche Modifikationen erfährt. So nimmt er etwa - unabhängig von Löwenfeld - eine aufschlußreiche Epochenzuweisung vor: Anstatt die Texte aber, was nahegelegen hätte, unter dem Vorzeichen des 'Realismus، zu lesen (wie vor ihm Liliencron), rückt er sie überraschenderweise in die Nähe der Romantik. ${ }^{14}$ Zugleich korrigiert Hofmannsthal, indem er Turgenevs Kurzprosa als Erscheinungsform mreiner Lyriku auffaßt, vorsichtig, aber bestimmt die Einschätzung des Übersetzers, der die Texte noch als "scheinbar flüchtig hingeworfene, ja fragmentarische kleine Erzählungen ${ }^{15}$ angesehen hatte. Die Selbstverständlichkeit, mit der er so den - mindestens ambivalenten - Gattungsstatus der Gedichte in Prosa in Richtung Lyrik vereindeutigt, verweist dabei klar auf die Deutungsgepflogenheiten der jungen Autorengeneration in Wien um 1890. Hofmannsthals Tagebuchnotiz gibt also nicht nur einen Einblick in die Poetik des Verfassers, sondern spiegelt zu einem nicht unbeträchtlichen Teil auch die ästhetischen Normen in jenem Segment des literarischen Feldes wider, in dem er selbst seinen Platz sucht. Die dezidierte Einordnung von Turgenevs kurzer Prosa in den Bereich der Lyrik dürfte übrigens entscheidend mit der zugleich konstatierten "Subjektivitätu der Texte zusammenhängen. $\mathrm{Da}$ Turgenevs Texte aber als subjektive Notate wirken konnten, verdanken sie einzig und allein der Form ihrer Darbietung. Beim Druck der Gedicbte in Prosa waren nämlich im Anschluß an jeden Text dessen Entstehungsmonat und -jahr angegeben - ein Umstand, welcher das Ensemble wie eine diaristische Zusammenstellung literarischer Momentaufnahmen erscheinen ließ. ${ }^{16}$ Hofmannsthal rezipierte denn auch die Kurzprosa des russischen Autors als meine Art lyrisches Prosatagebuch ( $\mathrm{H}-\mathrm{GW}$ X, S. 314) und äußerte in diesem Zusammenhang sogar die Absicht, etwas ähnliches selbst zu versuchen und mGedanken, oder 'Eindrücker oder 'Träume«, kurz: »das Leben dieses Sommers" (H-GW X, S. 314) entsprechend aufzuzeichnen. Allerdings blieb dieses Vorhaben unausgeführt. ${ }^{17}$

13 Zu Hofmannsthals mselektiver Wahmehmung bei der Rezeption der Stichosvorenija v proze insgesamt vgl. Christoph Perels: Gedichte in Prosa von Ivan Turgenev - gelesen vom jungen Hofmannsthal, S. 125.

14 Dafür waren wohl die sphantastischen Elemente in Turgenevs Texten verantwortlich.

15 Iwan Turgeniew: Gedichte in Prosa. Mit Autorisation des Verfassers übersetzt von R. [aphael] Löwenfeld, S. V.

16 Ein genauer Blick auf die einzelnen Texte zeigt freilich, „daß zwischen Datum und Gedichtinhalt oder Gedichtstruktur" gerade kein unmittelbarer "Zusammenhang westeht; Christoph Perels: Gedichte in Prasa von Ivan Turgenev - gelesen vom jungen Hofmannsthal, S. 127.

17 Spuren davon kann man aber noch in den insgesamt drei fertiggestellten Kurzprosatexten (Gerechtigkeit, Das Glück am Weg, Die Rast und der Scbribtiscb) Hofmannsthals entdecken, die allesamt mit dem Personalpronomen mich« beginnen. 
Weitere Impulse erhielt Hofmannsthals Gattungsverständnis dann rund ein Jahr später durch die Lektüre von Joris-Karl Huysmans' Roman $\dot{A}$ rebours (1884). ${ }^{18}$ Dort nämlich findet im 14. Kapitel, als die literarischen Vorlieben der ebenso gebildeten wie exzentrischen Hauptfigur, dem Duc Jean Floressas des Esseintes, beschrieben werden, die Textform Prosagedicht besondere Hervorhebung:

Des Esseintes [...] feuilleta une [...] plaquette qu'il avait fait imprimer, à son usage, une anthologie du poème en prose, une petite chapelle placée, sous l'invocation de Baudelaire, et ouverte sur le parvis de ses poèmes.

Cette anthologie comprenait un selectre du Gaspard de la nuit de ce fantasque Aloysisus Bertrand qui a transféré les procédés du Léonard dans la prose et peint, avec ses oxydes métalliques, des petits tableaux dont les vives couleurs chatoient, ainsi que celles des émaux lucides. Des Esseintes y avait joint le Vox populi, de Villiers, une pièce superbement frappée dans un style d'or, à l'effigie de Leconte de Lisle et de Flaubert, et quelques extraits de ce délicat Livre de Jade dont l'exotique parfum de ginseng et de thé se mêle à l'odorante fraicheur de l'eau qui babille sous un clair de lune, tout le long du livre.

Mais, dans ce recueil, avaient été colligés certains poèmes sauvés de revues mortes: le Démon de l'analogie, la Pipe, le Pauvre enfant pâle, le Spectacle interrompu, le Phénomène futur, et surtout Plainte d'automne et Frisson d'hiver, qui étaient les chefs-d'œuvre du poème en prose, car ils unissaient une langue si magnifiquement ordonnée qu'elle berçait, par elle-même, ainsi qu'une mélancolique incantation, qu'une enivrante mélodie, à des pensées d'une suggestion irrésistible, à des pulsations d'âme de sensitif dont les nexfs en émoi vibrent avec une acuité qui vous pénètre jusqu'au ravissement, jusqu'à la douleur.

De toutes les formes de la littérature, celle du poème en prose était la forme préférée de des Esseintes. Maniée par un alchimiste de génie, elle devait, suivant lui, renfermer, dans son petit volume, à l'état d'of meat, la puissance du roman dont elle supprimait les longueuers analytiques et les superfétations descriptives. Bien souvent, des Esseintes avait médité sur cet inquiétant problème, écrire un roman concentré en quelques phrases qui contiendraient le suc cohobé des centaines de pages toujours employeés à établir le milieu, à dessiner les caractères, à entasser à l'appui les observations et les menus faits. [...]

Le roman, ainsi conçu, ainsi condensé en une page ou deux, deviendrait une communion de pensée entre un magique écrivain et un idéal lecteur, une collaboration spirituelle consentie entre dix personnes supérieures éparses dans l'univers, une délectation offerte aux délicats, acces[s]ible à eux seuls. -

En un mot, le poème en prose représentait, pour des Esseintes, le suc concret, l'osmazome de la littérature, l'huile essentielle de l'art. ${ }^{19}$

Dadurch freilich, daß $\dot{A}$ rebours als narrative Umsetzung eines an der Maxime l'art pour l'art orientierten Kunstprogramms konzipiert war und Duc des Esseintes bei den Zeitgenossen folgerichtig als wdas reichste und deutlichste Beispiel der Décadence« (DJW I, S. 425) ${ }^{20}$ angesehen wurde, amalgamierte sich Huysmans' Poetik des

$18 \mathrm{Daß}$ Hofmannsthal das Buch spätestens im Juni 1891 kennenlernt hat, bezeugt eine auf den Protagonisten des Textes bezogene Tagebuchnotiz vom 16.6.; vgl. H-GW X, S. 333.

19 Euvres complètes de J.-K. Huysmans. Bd. 7: À rebours. Paris: Les Éditions G. Crès et Cie 1929, S. 300-302.

20 Bahrs Aufsatz Die Décadence (1891), der diese Bewertung enthält, wurde später - leicht verändert - in der Essaysammlung Studien zur Kritik der Modeme (1894) wiederabgedruckt. Auf 
Prosagedichts aufs engste mit dem Ästhetizismusdiskurs des fin de siècle. ${ }^{21}$ Und je nachdem, ob sich ein Autor eher zu einem mimetischen oder einem amimetischen Literaturverständnis bekannte, fiel auch meist die Bewertung der im Roman entwikkelten Essenztheorie ${ }^{22}$ aus.

Gemäß der für ihn charakteristischen Ambivalenz gegenüber den ästhetizistischen Bestrebungen seiner Zeit ${ }^{23}$ begegnete Hofmannsthal der hier gegebenen Deutung des Prosagedichts mit einer Mischung von Faszination und Abwehr. Einerseits mußte ihn die enge Bindung des Genres an den Roman irritieren, die seiner eigenen Einschätzung vom lyrischen Charakter der Textform widersprach und obendrein mit der österreichischen Gattungshierarchie konfligierte, andererseits aber übte der Gedanke, das poème en prose eröffne einen konkreten Weg, wie literarischer Ausdruck sprachlich maximal verdichtet werden könne, natürlich einen besonderen Reiz auf einen Schriftsteller aus, der selber darauf bedacht war, die Kunst auf das Wesentliche zu reduzieren. ${ }^{24}$ Ähnliches trifft auch auf das Verhältnis von Autor und

Grund der Faszinationskraft seines Protagonisten wurde $\dot{A}$ rebours vor allem außerhalb Frankreichs binnen kürzester Frist unkritisch zum "Gebetbuch der Décadence» stilisiert; Henri Albert: Pariser Brief. Bei Joris-Karl Huysmans. In: Freie Bühne für modemes Leben 5 (1894), S. 163. Friedell nennt den Text »den klassischen Roman der Décadence«; Egon Friedell: Kulturgeschichte der Neuzeit, S. 1469. Vgl. hierzu u.a. Hans Jürgen Greif: Huysmans' $A$ rebours und die Dekadenz. Bonn: Bouvier 1971 (= Abhandlungen zur Kunst-, Musik- und Literaturwissenschaft 115), François Livi: J-K. Huysmans. $A$ rebours et l'esprit décadent. O.O. [Bruxelles]: La Renaissance du livre 1972, sowie die Beiträge des Bandes: Huysmans. Une esthétique de la décadence. Actes du colloque de Bâle, Mulhouse et Colmar des 5, 6 et 7 nov. 1984, organisé par André Guyaux. Genève: Slatkine 1987 (= Travaux et recherches des universités rhénanes 1 ).

Dabei wird zwischen Symbolismus und Dekadenz häufig nicht genau unterschieden. Vilain bemerkt in diesem Zusammenhang zu Recht. wthere is evidence that Hofmannsthal was not always able to make a distinction, although he attempted to do sor, Robert Vilain: The Poetry of Hugo von Hofmannsthal and French Symbolism, S. 139. Am 20. März 1893 etwa subsumiert Hofmannsthal eine Folgeerscheinung des Ästhetizismus - mdas Auseinanderfallen des Ganzen; die Theile glühen und leuchten« - unter dem Schlagwort »Decadenz«; zitiert nach: ebd., S. 140.

22 Vgl. Klaus Meyer-Minnemann: Le roman concentré en quelques phrases. Zur Auffassung und Gestaltung des Prosagedichts bei J.-K. Huysmans. In: Romanistisches Jahrbuch 21 (1970), S. 181-194. Der Umstand, daß die weitgehende Homophonie des Namens "Esseintes" und des Begriffs "essencer einen deutschen Autor der Jahrhundertwende dazu animierte, den Titelhelden von $A \dot{A}$ rebours kurzerhand „Marquis von Essenz« zu nennen, kann als deutliches Indiz für die internationale Prägekraft von Huysmans' Roman im Hinblick auf die Gattung Prosagedicht genommen werden; vgl. Christian Morgenstern: Zwei Kapitel aus der satanischen Geschichte des Marquis von Essenz (J.K. Huysmans). In: Die Gesellschaft 18 (1902), S. 29-31.

23 Kalcher betont in diesem Zusammenhang besonders "Hofmannsthals ambivalente Haltung der Décadence gegenüber«; Joachim Kalcher: Perspektiven des Lebens in der Dramatik um 1900, S. 152.

24 Daß Hofmannsthal die literarische und speziell die poetische Tätigkeit als Prozeß des Ver- 
Leser zu, das in $\dot{A}$ rebours im Anschluß an Theoreme der deutschen Frühromantik ${ }^{25}$ sakralisierend als "communion de pensée entre un magique écrivain et un idéal lecteur" entworfen wird. Während der von Huysmans behauptete enge Rezipientenbezug des Prosagedichts fraglos faszinierend wirkte, strebte Hofmannsthal doch zu keinem Zeitpunkt eine hermetisierte Kommunikation nach dem Modell exklusiver wcollaboration spirituelle" zwischen wenigen ausgesuchten Aktanten an, sondern war im Gegenteil viel eher bestrebt, seine Dichtung in den sozialen Raum hinein zu öffnen. Im Grunde verbirgt sich hinter dem hier geäußerten Ideal die atavistische Sehnsucht, dem kommerzialisierten Verwertungskreislauf von Literatur in der Moderne zu entkommen, der Produzenten und Rezipienten gleichermaßen zu anonymen Größen macht und Kommunikation in einem emphatischen Sinn verhindert. Im Gegenzug zu dieser als verderblich angesehenen Entwicklung entwirft Huysmans ein Konzept, das die Verstehbarkeit von Texten auf einen sehr kleinen Kreis von Eingeweihten reduziert. Der Grund dafür, daß gerade das poème en prose als Musterbeispiel für solch ein esoterisches Gattungsmodell ausgerufen wird, ist wohl in dem Umstand zu suchen, daß dieses Genre auch in Frankreich einem breiteren Publikum noch unbekannt war und sich zugleich bei als avantgardistisch geltenden Autoren großer Beliebtheit erfreute.

Freilich darf die in $\dot{A}$ rebours vorgenommene Auratisierung des Prosagedichts nicht ohne weiteres als ästhetisches Credo des Autors genommen werden. Denn bezeichenderweise erfolgt die Diskreditierung der narrativen Großform als hoffnungslos redundantes Genre mit »longueuers analytiques et [...] superfétations descriptives» eben im Gattungskontext Roman, ${ }^{26}$ was im Gegenzug auch die Charakterisierung des poème en prose als mroman concentré« in ein etwas eigenartiges Licht rückt - zumal zwar Hinweise auf Autoren von Prosagedichten gegeben werden (wCette succulence développée et réduite en une goutte, elle existait déjà chez Baudelaire, et aussi dans ces poèmes de Mallarmé qu'il humait avec une si profonde joie. $\varkappa^{27}$ ), kon-

dichtens ansah, geht aus einem frühen Brief an Gustav Schwarzkopf hervor, wo es heißt: "Sie haben wieder einmal ein Stück Dichterarbeit getan, verdichtet, gefaltet.. Hugo von Hofmannsthal: Briefe 1890-1901. Hrsg. von Heinrich Zimmer. Berlin: S. Fischer 1935, S. 17. Der Autor partizipiert damit im übrigen am wsprachästhetischen und sprachmystischen Fundamentalismus« der Wiener Moderne, auf den in jüngerer Zeit vor allem Żmegač aufmerksam gemacht hat, Viktor Žmegač Die Wiener Moderne und die Tradition literarischer Gattungen, S. 204.

So hat Novalis bekanntlich postuliert, der wwahre Leser müsse »der erweiterte Autor seyn'; Novalis. Werke, Tagebücher und Briefe Friedrich von Hardenbergs. Hrsg. von Hans-Joachim Mähl und Richard Samuel. Bd. 2: Das philosophisch-theoretische Werk. Hrsg. von H.-J. M. München/Wien: Hanser 1978, S. 282.

26 Zur Stellung von $\dot{A}$ rebours in der Geschichte des Romans insgesamt vgl. Christopher Lloyd: J.-K. Huysmans and the fin-de-siècle-novel. Edinburgh: Edinburgh University Press 1990 (= University of Durham series 3). 
krete Textbeispiele aber ausbleiben. Vollends die reichlich überzogen wirkende Emphase, mit der das neue Genre angepriesen und zum Inbegriff künstlerischer Vollendung erklärt wird - »le suc concret, l'osmazome de la littérature, l'huile essentielle de l'art« -, verleiht Huysmans' Charakteristik ironische Züge. Es verbietet sich daher, die in $A$ rebours gegebene ,Definition kurzerhand zu sdem locus classicus zur Ästhetik des PGs [ = Prosagedichts] ( $^{28}$ zu erklären, stellt sie doch - genau besehen - nicht mehr als eine weitere Deutungsvariante im Prozeß konkurrierender kulturspezifischer Funktionszuweisungen dar.

Ob Hofmannsthal die verdeckte Ironie des Textes wahrgenommen hat (die sich im übrigen, mindestens partiell, auch auf Habitus und Wertekanon des Protagonisten erstreckt), läßt sich auf Grund der nur spärlich vorhandenen Quellen nicht sagen. Feststeht allerdings, daß die in Huysmans' Roman behauptete Kondensatqualität des Prosagedichts fortan sein Verständnis der Gattung mitgeprägt hat. Am deutlichsten wird dies an einer Tagebuchnotiz vom Sommer 1893, in der er - möglicherweise nach erneuter Lektüre der Gedichte in Prosa - an Turgenevs Texten besonders hervorhebt, daß sie »bloss angedeutet« seien; über ihren Autor heißt es bei dieser Gelegenheit anerkennend: mer sagt ungeheuer wenig überflüssiges “ ${ }^{29}$. Diese Äußerung, die eindeutig auf den Einfluß der poème-en-prose-Charakteristik in $\dot{A}$ rebours verweist, markiert - im Vergleich zu früheren Stellungnahmen des Autors - eine signifikante Änderung im Verständnis der Gattung, hat sich doch der Fokus vom Aspekt der Subjektivität und der Lyrisierung wcg auf Fragen des Umfangs und der Sprachökonomie verschoben.

Als weitere Ausprägungsform des Prosagedichts lernte Hofmannsthal im Laufe des Jahres 1892 schließlich noch Baudelaires Petits poèmes en prose kennen. ${ }^{30}$ Auch hier

28 Wilhelm Füger: Das englische Prosagedicht. Grundlagen, Vorgeschichte, Hauptphasen, S. 255.

29 Hugo von Hofmannsthal: Sämtliche Werke. Kritische Ausgabe, veranstaltet vom Freien Deutschen Hochstift. Hrsg. von Heinz Otto Burger, Rudolf Hirsch, Detlev Lüders, Heinz Rölleke, Emst Zinn. Bd. 29. Frankfurt a.M.: S. Fischer 1978, S. 397.

Die ersten Übersetzungen baudelairescher poèmes en prose im deutschen Sprachraum erschienen 1890 und 1891 in der Wiener Zeitung Moderne Rundschax, vgl. hierzu die bibliographischen Angaben bei Manfred Gsteiger: Französische Symbolisten in der deutschen Literatur der Jahrhundertwende (1869-1914). Daß Hofmannsthal schon früh Texte des französischen Autors kennengelemt hat, geht aus seinem am 1. Oktober 1891 in der Modemen Rundschau erschienenen Essay über Maurice Barrìs hervor, wo er von der "parfümschweren Atmosphäre fanierter, künstlicher und seltener Dinge, wie Baudelaire sie liebt« (H-GW VIII, S. 123), spricht. Wenig später dann zitiert er in dem autobiographischen Prosatext Age of Innocence (Februar 1892), ohne den Verfasser zu nennen, zwei Verse aus dem Fleurs du mal-Gedicht $\dot{A}$ une passante zitiert. Die Anregung, sich mit dem Werk Baudelaires intensiver zu beschäftigen, dürfte freilich von Stefan George ausgegangen sein, der 1892 seine »Umdichtung w der Fleurs du mal (1892) publizierte. So findet sich in Hofmannsthals Tagebuch schon unter dem Datum des 21. Dezember 1891 die Eintragung. "Stefan George. (Baudelaire, Verlaine, Mallarmé, Poe, Swinbume.) (H-GW X, S. 340) Explizit auf Baudelaire be- 
scheint die Begegnung spannungsreich verlaufen zu sein. ${ }^{31}$ Das hängt zunächst damit zusammen, daß Baudelaire ebenso wie Huysmans zu dieser Zeit als typischer Vertreter einer dekadenten Lebenseinstellung angesehen wurde. ${ }^{32}$ Mehr noch als dessen aggressive Selbstinszenienung als Bürgerschreck (die im übrigen scharf mit der klassizistisch wirkenden Formstrenge seiner Verslyrik kontrastiert) mußte den an die allegorische Moralistik turgenevscher Kurzprosa gewohnten Hofmannsthal freilich die Machart der Petits poèmes en prose irritieren, erlebte er hier doch zum ersten $\mathrm{Mal}$, wie existentielle Konfliktstrukturen textuell so konstelliert wurden, daß sie nicht in Handlungsanleitungen mündeten. Der Provokation durch die auf Schockerfahrung angelegte Drastik der Darstellung und die dahinter zu vermutende asoziale Attitüde des Autors ist es letztlich wohl zuzuschreiben, daß er sich wim September oder Oktober $1892 \varkappa^{33}$ nun auch selbst in dem für ihn neuen Genre versuchte und damit begann, eigene Kurzprosatexte zu entwerfen. ${ }^{34}$

zügliche Notizen enthalten die Aufzeichnungen von Juni/Juli 1892; vgl. H-GW X, S. 348 . Mittlerweile ist es der Forschung sogar gelungen, die Ausgabe zu benennen, in welcher der österreichische Autor die Prosagedichte seines französischen Kollegen vermutlich gelesen hat: „Hofmannsthal's copy of Baudelaire's prose poems was Petits Pömes en prose - Les paradis artificiels - par Charles Baudelaire (Paris: Calmann-Lévy, [n.d.]) - most probably the edition published in 1889." Robert Vilain: The Poetry of Hugo von Hofmannsthal and French Symbolism, S. 229, Anm. 62. Ob er freilich auch Aloysius Bertrands Gaspard de la nuit zur Kenntnis genommen hat, ist höchst ungewiß. Zwar finden sich zwei Erwähnungen des Werks in seinem Tagebuch, doch könnten sich diese Eintragungen auch der Lektüre der Petits poimes en prose verdanken, deren Widmungsvorrede an Arsène Houssaye ja Bertrand als Bezugspunkt explizit erwähnt. In Vilains griffiger Formulierung. wHofmannsthal's access to the genre was threefold, via Bertrand, Baudelaire and Turgenevu muß also Bertrand durch Huysmans ersetzt werden; ebd., S. 227.

Böschenstein resümiert denn auch: "Hofmannsthal mag sich von Einzelmotiven der Baudelaireschen Dichtung haben anregen lassen - seine Denkform ist der Baudelaires genau entgegengesetzt. Baudelaire hat bekanntlich die Reihe der poesiefähigen Gegenstände um solche erweitert, die bislang von den Dichtem streng gemieden wurden - das hat Hofmannsthal gerade nicht übernommen. Baudelaires große Thematik der negativen Theologie, die zur Satanologie wird, steht ihm denkbar fem. Baudelaires Methode des reflektierenden Selbstgesprächs setzt eine unausgesetzte Trennung zwischen dem Subjekt und seinen gegenständlichen correspondants voraus, die Hofmannsthals trawmbaftem Zusammennehmen aller Geschöpfe [...] widerspricht.“ Bernhard Böschenstein: Hofmannsthal, George und die französischen Symbolisten. In: Arcadia 10 (1975), S. 158-170.

32 Als Urheber dieses Deutungsstereotyps fungierte Gautier, der seinen Freund zum mpoëte de décadencer erklärte; Théophile Gautier: CEuvres complètes. [Réimpression des éditions: Paris: Charpentier 1878-1894.] Bd. IX/2: Portraits et souvenirs littéraires [1881]. Genève: Slatkine 1978, S. 194. Zur Entstehung der französischen décadence insgesamt siehe Erwin Koppen: Dekadenter Wagnerismus. Studien zur europäischen Literatur des Fin de siècle. Berlin/New York: de Gruyter 1973 (= Komparatistische Studien. Beihefte zu aradia 2). Hugo von Hofmannsthal: Sämtliche Werke. Kritische Ausgabe, Bd. 29, S. 397. meint: »Nicht die poèmes en prose der französischen Literatur bildeten den Anstoß zu ei- 
In den darauffolgenden 15 Monaten notierte er eine ganze Reihe von stichwortartigen Einfallen zu möglichen Prosagedichten in sein Tagebuch. Einige davon wuchsen sich zu regelrechten Entwürfen aus, und immerhin drei der so entstandenen Texte dürfen als abgeschlossen gelten: Die Rose und der Scbreibtisch, Gerecbtigkeit und Das Glück am Weg. Wie ernst es Hofmannsthal mit seinem Vorhaben tatsächlich war, verdeutlicht eine handschriftliche, "Prosagedichte" überschriebene Liste mit insgesamt 15 Einträgen, die vermutlich aus dem Jahr 1893 stammt. ${ }^{35} \mathrm{Um}$ so mehr muß erstaunen, daß der Autor im Endeffekt nur zwei davon veröffentlicht und diese wiederum beim Druck nicht als Prosagedichte gekennzeichnet hat. Während Gerechtigkeit ebenso wie Die Rose und der Schreibtisch unpubliziert blieben, erschien Das Glück am $W_{\text {eg am }}$ 30. Juni 1893 ohne Gattungsbezeichnung ${ }^{36}$ in der Deutschen Zeitung (Wien). Ein zunächst "Monografie einer Hand» benanntes Prosagedicht schließlich büßte ebenfalls seinen ursprünglichen Textstatus ein und wurde Teil eines Essays über Eduard von Bauemfelds dramatischen Nacblaß, den dic Frankfurter Zeitung am 6. Dezermber desselben Jahres brachte. ${ }^{37}$

Vor allem die beiden nicht veröffentlichten Kurzprosastücke belegen unmißverständlich, wie stark sich Hofmannsthal an Beispieltexten Turgenevs und Baudelaires orientiert hat. Was ihn daran vornehmlich anzog, war wohl die allegorische Konstel-

gener Produktivität auf diesem Gebiet, sondern die Gedichte in Prosa von Iwan S. Turgenjew《; Stefan Nienhaus: Das Prosagedicht im Wien der Jahrhundertwende. Altenberg - Hofmannsthal - Polgar, S. 142.

35 Während Die Rose und der Schreibtisch in der Liste fehlt, sind dort die Einträge »Monografie einer Hand", "Gerechtigkeit" und „Glück am Wegu sehr auffällig mit einem Stemchen versehen. Ob diese Kennzeichnung freilich indiziert, daß die Texte "sschon fertig waren", ist ungewiß; Hugo von Hofmannsthal: Sämtliche Werke. Kritische Ausgabe, Bd. 29, S. 398. Es kann sich dabei ebensogut um eine Merkhilfe handeln, die den Autor beispielsweise daran erinnern sollte, die hervorgehobenen Titel weiter zu bearbeiten.

Schon die Tatsache, daß Hofmannsthal den ohnehin recht umfangreichen Text in einem Brief an Marie Herzfeld vom 12. Juni 1893 als mallegorische Novelette« titulierte, führt vor Augen, wie sehr sich der Autor hier an konkurrierenden Muster narrativer Kurzprosa ausgerichtet hat; Hugo von Hofmannsthal: Briefe an Marie Herzfeld. Hrsg. von Horst Weber. Heidelberg: Stiehm 1967 (= Poesie und Wissenschaft 1), S. 37. Doch auch hier ist möglicherweise ein Bezug auf Baudelaire gegeben. So sieht etwa Renner das Versgedicht $\dot{A}$ une passante als "Intertextu für Das Glück am Weg an; Ursula Renner: "Die Tiefe muß man verstecken - Wo? An der Oberflächer. Allegorisierung als Verfahren der Moderne in Hofmannsthals Glïck am Weg. In: Austriaca. Cahiers universitaires d'information sur l'Autriche, Nr. 37, 1993, S. 257.

37 Wunberg hat in diesem Zusammenhang zu Recht auf die "Näher von Hofmannsthals Prosagedichten »zu seinen frühen Essays" und ihre munmittelbare Herkunft aus den Aufzeichnungen [...] und Tagebüchern hingewiesen; Gotthart Wunberg: "Ohne Rücksicht auf Inhalt - lauter Venerabiliau. Überlegungen zu den Prosagedichten Hugo von Hofmannsthals. In: ebd., Nr. 37, 1993, S. 320. So hat der Autor etwa eine auf seine Bekannte Lili Schalk bezogene Aufzeichnung später "so gut wie wörtlich in das Prosagedicht Gerechtigkeit übernommen«; ebd., S. 321. 
lierung traumartiger Erfahrungen auf engstem Raum. ${ }^{38}$ Der erkennbar wchiffrenhafte Charakter der [...] verwandten Realien ${ }^{39}$ deutet dabei auf jenes antinaturalistische Literaturverständnis hin, das für ihn selbst charakteristisch ist. Doch während die Texte des russischen Autors offenkundig weitgehend fraglos als Vorbilder gedient haben, ${ }^{40}$ fungierten diejenigen Baudelaires eher als Gegenmodelle. ${ }^{41}$ Nicht nur, daß Hofmannsthal ganz ähnlich wie Turgenev existentiell aufgeladene, allegorische Szenarien entwarf, ${ }^{42}$ die reichlich abstrakte Sachverhalte - wie das Verhältnis von Kunst und Natur bzw. Kunst und Leben ${ }^{43}$ (Die Rose und der Schreibtiscb) oder die Frage nach

38 Konsequent angewandt führt die von Huysmans empfohlene Extraktmethode fast notgedrungen zu einer Allegorisierung der Texte.

39 Helmut Koopmann: Entgrenzung. Zu einem literarischen Phänomen um 1900, S. 76. Nienhaus führt diesen Gedanken fort: "Somit wird die allegorisierende Erzählweise zu einer Darstellung dessen, was als nicht mehr unmittelbar Zugängliches vorgestellt werden muß: des Begriffs. « Stefan Nienhaus: Das Prosagedicht im Wien der Jahrhundertwende. Altenberg - Hofmannsthal - Polgar, S. 172.

40 Die herausgehobene Bedeutung, die Hofmannsthal den Gedichten in Prosa zuerkannte, zeigt sich nicht zuletzt daran, daß Turgenevs Sammlung als eines von nur vier Werken der russischen Literatur in die von ihm win enger Beratung mit dem Verleger Anton Kippenberg konzipierte, auf insgesamt 100 Bände angelegte Anthologie von Texten der Weltliteratur Aufnahme fand, die im Frühjahr 1920 unter dem Titel »Pandora» angekündigt wurde; Christoph Perels: Gedichte in Prosa von Ivan Turgenev - gelesen vom jungen Hofmannsthal, S. 122, Anm. 8. Perels bemerkt denn auch zu Recht: »Dieses Werk [...] begleitete Hofmannsthal sein Leben lang." Ebd.

41 So steht etwa die Aufwertung des Natürlichen in Die Rose und der Schreibtisch in deutlichem Kontrast zu Baudelaires Poetik der Künstlichkeit bzw. Widematürlichkeit. Sucht man nach intertextuellen Bezügen zwischen Hofmannsthals Prosagedichten und denen seiner Vorgänger, so zeigt sich, daß Die Rase und der Schreiblisch offenkundig auf $L a$ Chambre double und Roza (Die Rose), vielleicht auch auf Perte d'auréok, Bezug nimmt; Gerechtigkeit mutet demgegenüber wie eine varïerende Neugestaltung von Prirada (Die Nalur) an, ergänzt durch Motive aus Dea brata (Zuei Brïder).

Tarot spricht in diesem Zusammenhang abwertend von "verkrampfter Allegorisierungus Rolf Tarot: Hugo von Hofmannstahl. Daseinsformen und dichterische Struktur. Tübingen: Niemeyer 1970, S. 303. Renner dagegen unterstreicht: "Allegorisierung, d.h. das Sprechen auf einer literalen und auf einer anderen, figuralen Ebene, ist seiner Darstellung wesentlich», und erläutert ihre Aussage folgendermaßen: "Die Allegorie wird für Hofmannsthal zum rmodemen Stilmittel dort, wo es dem Dichter gelingt, sie aus den abgegriffenen semantischen Festschreibungen zu befreien.، Ursula Renner. „Die Tiefe muß man verstecken - Wo? An der Oberflächer. Allegorisierung als Verfahren der Modeme in Hofmannsthals Glück am Weg, S. 253 und 254.

$\mathrm{D} a ß$ dieses Verhältnis eine zentrale Rolle in der Poetik des jungen Hofmannsthal einnimmt und Reflexionen darüber dessen mgesamte frühe Dramatik« durchziehen, hat überzeugend und mit einigen neuen Akzenten Streim gezeigt; Gregor Streim: Das seben in der Kunst. Untersuchungen zur Ästhetik des frühen Hofmannsthal. Würzburg: Königshausen \& Neumann 1996 (= Epistemata. Reihe Literaturwissenschaft 171), S. 141. Unverständlich bleibt freilich, warum Streim gerade Die Rose und der Sclbreibtisch unberücksichtigt gelassen hat. 
den Kriterien richtiger Lebensführung (Gerechtigkeit) - thematisieren, ${ }^{44}$ er vermied auch genau wie dieser jegliche Ironisierung des Dargestellten und setzte so den ethisch indifferenten, nicht selten sogar zynisch wirkenden Spielanordnungen der baudelaireschen Petits poèmes en prose faktisch spositiver Beispiele literarischer Moralistik entgegen. ${ }^{45}$ Es scheint also, daß hier wie dort ein vergleichbarer Impuls die Werkproduktion angestoßen hat.

Anders als Turgenev freilich verzichtete Hofmannsthal darauf, seine Prosagedichte als Prosagedichte in der Öffentlichkeit zu präsentieren. Das kann nur verwundern angesichts der Tatsache, daß er sich faktisch insgesamt dreieinhalb Jahre lang mehr oder weniger intensiv mit diesem Genre beschäftigt hat und es immerhin über einen Zeitraum von 15 Monaten hinweg ein zentraler Faktor seiner literarischen Produktion war. Zur Gänze ins Licht tritt die erhebliche Bedeutung der Gattung für Hofmannsthals Frühwerk aber erst, wenn man beide Intervalle mit seinem geringen Alter und der kurzen Spanne seiner bisherigen schriftstellerischen Tätigkeit - der österreichische Autor war Ende 1893 noch nicht einmal 20 Jahre alt, seine erste Publikation lag gerade einmal drei Jahre zurück - korreliert. Fragt man nach den Gründen, die einer konsequenteren Nutzung des Textmodells Prosagedicht entgegenstanden, so liegt es zunächst nahe, eine Erklärung im Bereich der Gestaltungstechnik zu suchen. Denn schon in einer frühen Aufzeichnung aus dem Jahr 1889 konstatiert Hofmannsthal, daß er die meidige Gewohnheit des Ausmalens und Erschöpfenwollens« (H-GW X, S. 313) habe. ${ }^{46}$ Seiner Ansicht nach verfüge er - zumindest in der Prosa - nicht über jenen "Telegraphenstil ( $\mathrm{H}-\mathrm{GW}$ X, S. 314), den er in der Geschichte literarischer Formen kontinuierlich sich ausbreiten sieht und den er offensichtlich auch als konstitutiv für das Prosagedicht betrachtet. Und tatsäch-

44 Daß die von ihm verfaßte Kurzprosa »keiner Intention des Erzählens, der Darstellung oder des Berichtens« mehr "gehorcht", trifft demnach nicht zu; Gotthart Wunberg: "Ohne Rücksicht auf Inhalt - lauter Venerabiliaw. Überlegungen zu den Prosagedichten Hugo von Hofmannsthals, S. 324.

Daß Hofmannsthal vor allem mit der französischen moralistischen Tradition vertraut war, geht aus einem Brief an Hermann Bahr von Ende 1891 hervor. Dort heißt es ebenso selbstbewußt wie indigniert: wich habe MM. de la Rochefoucauld de la Bruyère, de St. Simon, de Montaigne, den Montesquieu, de Buffon, soqie die Herren Chamfort, Courier, Chateaubriand, Voltaire, La Mettrie, Louvet, Jean Jacques, Diderot, Prévost, Gresset, Mably und (hélas!) Volney auch gelesen«; Hugo von Hofmannsthal: Briefe 1890-1901, S. 33. Bei Turgenev und den Moralisten fand Hofmannsthal im übrigen auch jene "Resignationsphilosophie" (H-GW VII, S. 25) vor, die sich der österreichische Autor in dem autobiographischen Jugendwerk Age of Innacence (1891) selbst zuschrieb.

46

Auch Rieckmann bemüht diese Selbstdeutung zur Beantwortung der Frage, swarum Hofmannsthal in den Jahren 1889 bis 1893, in denen er als Lyriker, Essayist und Dramariker äußerst produktiv ist, als Erzähler in den meisten Fällen nicht über das Stadium der skizzenhaften Konzeption hinauskommtc; Jens Rieckmann: Aufbruch in die Modeme. Die Anfänge des Jungen Wien. Österreichische Literatur und Kritik im Fin de Siècle. Königstein i.Ts.: Athenäum 1985, S. 175. 
lich überschreitet Das Glück am Weg als einziger Kurzprosatext, den der junge Hofmannsthal publiziert hat, deutlich den für die Gattung üblichen Umfang.

Das weitaus größere Hindernis für eine umfassende Aneignung des Textmodells dürfte allerdings seine eigentümliche Formlosigkeit dargestellt haben, verfügte das Prosagedicht doch nicht mehr über einen generischen Satz von Gattungsmerkmalen, mit dessen Hilfe ein verläßliches Genremuster zu etablieren gewesen wäre. Wunberg hat in diesem Zusammenhang die Vermutung geäußert, wdass Hofmannsthal immer dort mit seinen Texten nicht fertig wird, im wahren Wortsinne, wo die vorgegebene Form nicht streng und deutlich genug ist ${ }^{47}$. Doch auch ohne schaffenspsychologische Begründungen zu Hilfe zu nehmen, wird man sagen können, daß der Autor nachhaltig bestrebt war, eine wohldefinierte Struktur für seine Texte zu finden. In einem Brief an George vom 8. Dezember 1892 etwa weist er explizit auf seinen ausgeprägten "Formsinn ${ }^{48}$ hin. Als er dann im Mai 1893 das Vorhaben entwickelte, "Dialoge über die Kunst« (H-GW X, S. 360) zu schreiben, setzte er sich ausführlich mit dem Problem der »Formlosigkeit in einem Kunstwerk» auseinander. Er notiert diesbezüglich: „Man weiß nicht, was man damit anfangen soll« und benennt unmittelbar im Anschluß daran die konkrete Leistung künstlerischer Formgebung: „Form hinterläßt Harmonie, Befriedigung [...]; gibt eine Ahnung der kosmischen Harmonie« (H-GW X, S. 361). Bereits viel früher schon, am 27. November 1890, hatte Hofmannsthal die Leistung der Form folgendermaßen charakterisiert: wSchönheit der Form bannt und erhält den Stimmungszauber wie das Gefäß den Wein: ein Aphorisma, einst lebhaft gefühlt, kann uns unverständlich werden; die abgeschlossene Form soll es organisch, lebensfähig machen.« (H-GW X, S. 315)

Im Gefolge dieser Überlegungen bildete sich bei ihm rasch eine relativ klare Gattungshierarchie heraus, in der das Drama den obersten Rang einnahm: „Das Drama ist die vornehmste Kunstform, weil darin am meisten verschwiegen wird" (H-GW X, S. 372), heißt es in einer Tagebuchnotiz aus dem Jahr 1893 oder 1894. Zwar bot - wie der Autor durch Huysmans vermittelt bekam - auch das Prosagedicht prinzipiell die Möglichkeit, sungeheuer wenig überflüssiges« zu sagen, was dem Genre jedoch fehlte, war eine klare Form, die es gestattet, zuverlässige Kommunikationsstrukturen zu installieren. Das Prosagedicht wird also von Hofmannsthal nicht mehr genutzt - und zwar seit $1894^{49}$-, weil hier wdie Direktiven der Form unklar sind ${ }^{50}$.

47 Gotthart Wunberg. "Ohne Rücksicht auf Inhalt - lauter Venerabiliar. Überlegungen zu den Prosagedichten Hugo von Hofmannsthals, S. 324.

Briefwechsel zwischen George und Hofmannsthal. Zweite ergänzte Auflage. [Hrsg. von Robert Boehringer.] München/Düsseldorf: Helmut Küpper 1953, S. 51.

$\mathrm{Da}$ der Gattungsbegriff "Prosagedicht" nach dem Jahr 1893 nicht mehr in Hofmannsthals Aufzeichnungen auftaucht, gibt es weder Anlaß noch Berechtigung dafür, spätere Texte und Notizen diesem Genre zuzuschlagen, wie das Ellen Ritter, die Herausgeberin der historisch-kritischen Ausgabe tut. So erklärt sie kurzerhand »Entwürfe« für Bildbeschreibungen »aus dem Jahr 1895 « zu Vorstufen für Prosagedichte und behauptet darüber hinaus so- 
Allerdings wscheiterte er nicht einfach daran; vielmehr erweist sich das vermeintliche "Versagen ${ }^{51}$ vor diesem Gattungsmodus als bewußte Abwendung von einer verwirrend vielgestaltigen Textsorte, deren hybrider Charakter sie ungeeignet erscheinen läßt, um unter den Bedingungen der Moderne noch zuverlässig ästhetische Kommunikation herzustellen. Wenn sich der einzige veröffentlichte Kurzprosatext des Autors von Umfang, Aufbau und Handlungsstruktur her stark dem Muster der Erzählung annähert, dann kann das als deutliches Indiz für eine Orientierung an sichereren Gattungsschemata gelten. ${ }^{52}$

Überhaupt richtete Hofmannsthal im Verlauf der neunziger Jahre seine literarische Produktion immer deutlicher an der sklassischen Gattungstrias aus. Das Drama steht dabei unangefochten an erster Stelle und wird flankiert von der Verslyrik und einem kleinen Spektrum von Prosaformen, das sich vornehmlich zwischen Novelle und Märchen bewegt. Obgleich manche dieser Genres durchaus eine recht eigenwillige Nutzung erfahren, fehlen beim erwachsenen Hofmannsthal im eigentlichen Sinn experimentelle Textsorten. Dennoch verschwindet das Prosagedicht nicht völlig aus seinem Gesichtsfeld. Auch wenn er sich des Gestaltungsmusters in der eigenen dichterischen Praxis nicht mehr bedient, beobachtet er doch weiterhin aufmerksam die Entwicklung der Gattung. ${ }^{53}$ Als 1896 dann mit Peter Altenberg ein weiterer

gar: "Auch die vermutlich 1898 entstandenen Aufzeichnungen Gedicht der Muscheln [...] und Betrachtung [...] sowie die beiden Notizen [...] vom 19. September 1916 sind als Prosagedichte anzusehenж; Hugo von Hofmannsthal: Sämtliche Werke. Kritische Ausgabe, Bd. 29, S. 398. Sie konstruiert auf diese Weise eine Werkkontinuität, die so nie existiert hat. Ähnlich wie Ritter ging wenig später auch Bernd Schoeller in seiner Edition der Gesammelten Werke vor; vgl. H-GW VII, S. 441-455. Nienhaus hat im Hinblick auf diese äußerst fragwürdige editorische Praxis mit gutem Grund die Frage aufgeworfen, wwas denn eine auf rein Privates bezogene Tagebuchnotiz eines Autors schon per se zum Prosagedicht qualifizieren kann«; Stefan Nienhaus: Das Prosagedicht im Wien der Jahrhundertwende. Altenberg - Hofmannsthal - Polgar, S. 141. Allerdings hielt ihn das nicht davon ab, fünf Texte aus den Jahren 1898 bis 1924 dann doch wieder der Gattung zuzuschlagen. Es bleibt demgegenüber festzuhalten: Hofmannsthal war nur in den Jahren 1892 und 1893 nachweislich mit der Planung und Abfassung eigener Prosagedichte beschäftigt. Gotthart Wunberg. „Ohne Rücksicht auf Inhalt - lauter Venerabiliaw. Überlegungen zu den Prosagedichten Hugo von Hofmannsthals, S. 324. Ebd., S. 324 und 325.

52 Žmegač konstatiert um 1900 generell ein starkes „Bestreben, der als Formzerfall gedeuteten naturalistischen und impressionistischen Prosa mit der Emeuerung fester, geschlossener Erzählungstypen zu begegnenc; Viktor Žmegač: Kunst und Ideologie in der Gattungspoetik der Jahrhundertwende [1980]. In: V. Ż.: Tradition und Innovation. Studien zur deutschsprachigen Literatur seit der Jahrhundertwende. Wien/Köln/Weimar: Böhlau 1993 (= Literatur in der Geschichte - Geschichte in der Literatur 26), S. 90. So dürften ihm etwa Teile von Liliencrons Kurzprosa vertraut gewesen sein. Jedenfalls äuBerte Hofmannsthal in einer nach dessen Tod zusammengestellten Gedenkpublikation: "Ich verkenne an ihm nicht den Hauch von Genie; ich freue mich hier und da an seinen Sachen sehri; Fritz Böckel: Detlev von Liliencron. Erinnerungen und Urteile, S. 64. 
Vertreter der Wiener Moderne das Genre erprobt, ergreift Hofmannsthal sofort die Gelegenheit, die unter der Überschrift Wie ich es sebe versammelten Prosagedichte und die dahinter stehende Ästhetik ihres Autors in einer ausführlichen Rezension zu analysieren. $^{54}$

Allerdings steht nicht etwa die reflexive Erörterung des Gattungsmodells selbst im Mittelpunkt des Ein neues Wiener Buch betitelten Aufsatzes; vielmehr legt Hofmannsthal seinen Text - über den unmittelbaren Anlaß weit hinausgehend - als grundlegende Auseinandersetzung mit den jüngsten ästhetischen Strömungen seiner Zeit an, die unübersehbar zum Ziel hat, den eigenen literarischen Standort bestimmen zu helfen. ${ }^{55}$ Am Beispiel Altenberg untersucht er eine kulturelle Rahmenkonstellation, die letztlich auch ihn selbst und sein Schreibprojekt (mit-)prägt - und genau dieser Umstand ist es auch, der den Essay so intrikat macht und beständig zwischen punktueller Anerkennung und grundsätzlicher Ablehnung oszillieren läßt. Seine Kritik versteckt Hofmannsthal dabei mit großer rhetorischer Finesse hinter höflich und konziliant klingenden Formulierungen. Läßt man diese aber einmal beiseite, dann enthüllt sich die auf den ersten Blick sehr wohlwollend-freundlich wirkende Buchbesprechung als eine scharfe Abrechnung mit dem künstlerischen Programms Altenbergs. ${ }^{56}$ So bezichtigt Hofmannsthal den Autor nicht nur der eitlen

54 Die auf den ersten Blick ebenso bescheiden wie unspezifisch klingende Überschrift von Hofmannsthals Besprechung, Ein neues Wiener Buch, ist mit großer Wahrscheinlichkeit als korrigierende Replik zu Hermann Bahrs enthusiastischem Artikel Ein never Dichser, der am 2. Mai 1896 in der Zeit erschienen war, konzipiert. Bahr hatte - anhand der Texte - vor allem auf die Eigentümlichkeit der Person Altenbergs hingewiesen und diesen als neue und originelle Dichtergestalt gewürdigt: „Diese Stimme haben wir noch nie vemommen; hier spricht jemand, den wir nicht mehr vergessen können. In seinem Munde wird jedes Wort neu und lebt auf; wir glauben es zum ersten Male zu hören. Es ist nicht mehr irgend ein Wort, das allen gehört, eines von den vacierenden Worten der Journalisten, das jedem zuläuft; es ist sein Wort geworden, seine Seele hat es sich angeeignet und gibt es nicht mehr her." (DJW I, S. 588) Und er hatte Altenberg als cine Art Prophetengestalt gepriesen, der, obzwar er lauter maltösterreichische Menschen darstelle, doch wuns in der Ferne ein neues Oesterreich sehen (DJW I, S. 589) lasse. Hofmannsthal dagegen lenkt in seiner Rezension vier Monate später - fast programmatisch - den Fokus der Betrachtung von der Person des Autors auf die Texte zurück.

55 Daß Hofmannsthals Essays durchweg, selbst wenn es sich dabei murr um Buchbesprechungen handelt, ganz eigentümliche reflexive und ästhetische Qualitäten aufweisen, hat die Forschung frühzeitig erkannt; vgl. etwa Amo Scholl: Hofmannsthals essayistische Prosa. Studien zur Entwicklung ihrer Form. Diss. Mainz 1958, sowie Ernest Otto Gerke: Der Essay als Kunstform bei Hugo von Hofmannsthal. Lübeck/Hamburg: Matthiesen 1970 (= Germanische Studien 236).

56 Barker spricht in diesem Zusammenhang von Hofmannsthals mimplicit denial of Altenberg's artistic autonomyc; Andrew Barker: „Die weiseste Ökonomie bei tiefster Fülle» - Peter Altenbergs Wie ich es sehe. In: Studies in Nineteenth Century Austrian Literature. Six Papers. Ed. by B.O. Murdoch and M.G. Ward. Glasgow: Thomson Litho 1983 (= Scottish Papers in Gemanic Studies 3), S. 82. 
Selbstgefälligkeit ( Das Buch [...] gefällt sich selbst; es ist sicher zu gefallen«; H-GW VIII, S. 225) und der maltklugen Koketterie» (H-GW VIII, S. 223), sondern wirft ihm auch künstliche Gefühlsübersteigerung (»maniriert", "preziös«; H-GW VIII, S. 225) sowie latente Anbiederung beim Leser (rallzu süß«; H-GW VIII, S. 223) vor.

Letztlich reduzieren sich die Vorbehalte gegen Altenbergs Prosagedichte auf zwei eng miteinander verknüpfte Argumente: Zum einen wirft Hofmannsthal dem Kollegen vor, daß er den nutzlosen - weil mschwachen und kläglichena - Versuch unternehme, wdem Leben von der Oberfläche her beizukommen (H-GW VIII, S. 220), da er sich ausschließlich mit walltäglichen Dingen« beschäftige und wmit gutem Gewissen Nichtigkeiten « (H-GW VIII, S. 225) anbete. Zum anderen diagnostiziert er in dessen Texten eine fatale Vermischung von Leben und Kunst. Anstatt eine ästhetisch notwendige Distanz aufzubauen und sich ein Stück weit waus dem Leben zurückzuziehen ( (H-GW VIII, S. 223) der ihn umgebenden Realität. ${ }^{57}$ Dies gehe soweit, daß «das Leben völlig als Material der Kunst erscheint « (H-GW VIII, S. 227). ${ }^{58}$ Sinn und Zweck der Literatur liegen nach Hofmannsthal aber nicht in der dekorativen Ästhetisierung der Wirklichkeit, sondern darin, mit Hilfe von Worten das Leben künstlerisch nachzuschaffen. Diese für ihn konstitutive Differenz zwischen lebensweltlicher Realität und Kunst hat er andernorts noch einmal unterstrichen. So heißt es in dem wenige Monate vor der Altenberg-Rezension erschienenen Aufsatz Poesie und Leben (1896) mit kategorischer Entschiedenheit: »Es führt von der Poesie kein direkter Weg ins Leben, aus dem Leben keiner in die Poesie.، (H-GW VIII, S. 16)

Altenbergs Scheitern liegt demnach in seiner irrigen Auffassung vom Status der Kunst begründet. Gerade weil er dem Leben Priorität einräume, unterschätze er beim Schreiben die Funktionsbedingungen von Literatur, deren Leistung letztlich in ästhetischer Formgebung bestehe. Hiermit ist ein weiteres wichtiges Thema des Textes bezeichnet, das Hofmannsthal zwar umkreist, zugleich aber im Impliziten beläßt. Näher erörtert wird es in den zeitgleich entstandenen Arbeitsnotizen, die im übrigen intertextuell eng mit der essayartigen Rezension verknüpft sind. ${ }^{59}$ So heißt

57 In der George-Rezension heißt es diesbezüglich unmißverständlich: „Es ist ein Hauptmerkmal der schlechten Bücher unserer Zeit, daß sie gar keine Entfernung vom Leben haben: eine lächerliche korybantenhafte Hingabe an das Vorderste, Augenblickliche hat sie diktiert.« (H-GW VIII, S. 215).

58

"Auch der Mensch ist ein Künstler, sollte es sein - - ein Lebens-Künstler!k heißt es etwa programmatisch in dem Prosagedicht Der Besuch (Ws, S. 112). Hofmannsthal begreift Altenberg denn auch als eitlen Poseur.

59 Der enge Wechselbezug beider zeigt sich auch darin, daß ein Tagebucheintrag fast wörtlich in Hofmannsthals Besprechung wiederkehrt. Während es in der privaten Aufzeichnung heißt: "Engländer: so ein Buch schreibt nur einer, dem die Welt glücklich und schön umhängt ist mit den Gewändern der Götter." (H-GW X, S. 419), ist im Text der Besprechung dann zu lesen: »Die Namen sehr großer Schauspieler [und Dichter] gehören zu den bunten 
es in einer auf Altenberg - der mit bürgerlichem Namen Richard Engländer hieß bezüglichen Tagebucheintragung explizit:

Engländer schwankt an der Grenze eines Zustandes hin, den Schiller definiert hat (Anmut und Würde): ,... die poetisierende Einbildungskraft sinkt zuweilen auch ganz zu dem Stoff zurück, aus dem sie sich losgewickelt hatte ...l und früher: )... dadurch, daß man der Materie Form erteilt: denn der Geist kann nichts als was Form ist, sein eigen nennen.4 (H-GW X, S. 418$)^{60}$

Altenberg selbst wird an dieser Stelle - zusammen mit Maeterlinck - zu einer Gruppe von Künstlern gezählt, die sich zum Ziel gesetzt haben, "das Unbestimmte« darzustellen, infolgedessen aber wdas wahre Gebiet der Kunst« (ebd.) verlassen. Denn: "Was sie an Freiheit gewinnen, geht ihnen an Konsistenz ab.« (Ebd.) Damit nun aber rückt unübersehbar der Aspekt der Form ins Zentrum der Auseinandersetzung. Hofmannsthal hat sich in dem programmatischen Essay Poesie und Leben ja ganz dezidiert gegen wdas Formlose “ (H-GW VIII, S. 15) in der Literatur gewandt und sich selbst ausdrücklich als »Dichter« charakterisiert, der »die Regeln lobt und in Wortfolgen und Maßen das Ganze der Poesie sieht« (H-GW VIII, S. 18). ${ }^{62}$ Wenn er seinen Kollegen also öffentlich mit für die Textsorte Buchbesprechung ungewöhnlich pathetischer Diktion zu größerer künstlerischer Ernsthaftigkeit ermahnt: »Es gibt eine zurückhaltendere Art, dem Leben zu huldigen, eine größere, herbere Art, ihm zu sagen, daß es grenzenlos wundervoll, unerschöpflich und erhaben ist und wert,

Gewändem der Götter, mit denen dieser Lebensgarten höchst künstlich umhängt ist. « (HGW VIII, S. 227)

60

Die beiden Zitate aus Schillers Abhandlung Öber Anmut und Würde (1793) finden sich bezeichnenderweise in einer Fußnote, die dem "Dichtergenie" gewidmet ist. Der Autor unterstreicht dort, wie wichtig es für ein mit Genie begabtes Künstlersubjekt doch sei, mbeizeiten darauf [zu] denken, sich dieses zweideutigen Geschenks durch den einzigen Gebrauch zu versichern, wodurch Naturgaben Besitzungen des Geistes werden können“, nämlich Formgebung. Im Falle, daß dies nicht geschieht, prophezeit er: "Durch keine verhältnismäßige Kraft der Vernunft beherrscht, wird die wild aufgeschossene üppige Naturkeraft über die Freiheit des Verstandes hinauswachsen und sie [...] ersticken [...]. / Die Erfahrung, denke ich, liefert hievon reichlich Belege, besonders an denjenigen Dichtergenien, die früher berühmt werden, als sie mündig sind, und wo [...] das ganze Talent oft die Jugend ist. Ist aber der kurze Frühling vorbei, und fragt man nach den Früchten, die er hoffen ließ, so sind es schwammige und oft verkrüppelte Geburten, die ein mißgeleiteter blinder Bildungstrieb erzeugte [...], und die vielversprechenden Meteore erscheinen als ganz gewöhnliche Lichter wo nicht gar als noch etwas weniger." Wird dieser Kontext als Verstehenshintergrund mitgedacht, erscheint Altenberg in Hofmannsthals Augen als eminent gefährdeter, da nicht einmal genialer (mein Mensch, der kein Genie ist،; H-GW VIII, S. 226) Dichterdebütant, dem es durch die Privilegierung des Genres Prosagedicht und die damit verbundene Vernachlässigung wohldefinierter Ausdrucksmuster nicht gelingt, »daß der Stoff sich zur Form veredeltu; Friedrich Schiller: Sämtliche Werke, Bd. 5, S. 457f., Anm. 1.

61 Er zitiert in diesem Zusammenhang zustimmend Äußerungen Georges, die in dem Diktum gipfeln: »den Wert der Dichtung entscheidet [...] die Form» (H-GW VIII, S. 16). 
mit dem Tod bezahlt zu werden« (H-GW VIII, S. 223), dann verweist dies nicht zuletzt auch auf den Formaspekt der rezensierten Texte. Liest man die zitierte Passage darüber hinaus im Kontext der ebenfalls 1896 entstandenen Rezension der Gedichte von Stefan Geonge, enthüllt sich Hofmannsthals Stellungnahme sogar als direkter Kommentar zum Gattungscharakter von Altenbergs Kurzprosa. ${ }^{62}$ Während an Georges Gedichten besonders »die herbe und strenge Form« gewürdigt wird, die weine beflügelte Stimmungu verbreite, sei es in Altenbergs Texten gerade »das Vage« und »das Abstrakte«, welches den Leser miederschlägt火 (H-GW VIII, S. 220). Dem Aspekt der Formgebung kommt vor allem deshalb herausgehobene Bedeutung zu, weil er als Chiffre für die gelungene oder mißlungene symbolische Bewältigung von Realität und deren Transformation in Kunst fungiert.

Hofmannsthal korreliert kurzerhand Verslyrik mit Form, Kurzprosa aber mit Formlosigkeit oder -nachlässigkeit. $\mathrm{Da}$ aber nur das »ewigu »lebt«, was der Künstler "zur Form emportreiben konntew (H-GW VIII, S. 24) - wie es später in der Ansprache im Hause des Grafen Lanckoroniski heißt -, kommt das faktisch einem Verdikt gegen das Genre Prosagedicht gleich. Der Hauptvorbehalt richtet sich dabei offensichtlich auf die dem Textmodell zugeschriebene Tendenz zu formaler Unbestimmtheit (darüber hinaus spielt auch das Argument des angeblichen Verhaftetseins im Stofflichen eine Rolle). Als ästhetisch defizient erweise es sich vor allem deshalb, weil es im Gegensatz zur Verslyrik, die - unabhängig von der individuellen Begabung eines Autors - per se zumindest den Vorteil äußerer Strukturiertheit hat, auch in den Händen eines Genies $^{63}$ seine eigentümliche amorphe Unbestimmtheit nie ablegen könne. Die Rezension von Wie ich es sehe ist mithin auch eine - wenn auch verdeckte - retrospektive Abrechnung mit den eigenen Versuchen in dieser Gattung.

Obwohl Hofmannsthals Prosagedichte, da sie entweder unveröffentlicht blieben oder in andere Textgestalten transformiert wurden, keinen Einfluß auf die Entwicklung der Gattung ausüben konnten, spielen sie für Autorwerdung und Poetik des

62 Die in der Rezension vorgenommene Identifizierung der »kleinen Geschichten (H-GW VIII, S. 222) als whleine Gedichten (H-GW VIII, S. 224) indiziert ebenso diskret wie unübersehbar, daß Hofmannsthal die Texte in Wie ich es sehe als Prosagedichte rezipiert hat. Als völlig verfehlt erscheint demgegenüber der Versuch, den sessay as [...] a prose-poem meditation on some of Hofmannsthal's favorite themes and idealsw lesen zu wollen; E.F. Block: Hofmannsthal's Ein nekes Wiener Buch reconsidered. In: The Germanic Review 52 (1977), S. 199.

$63 \mathrm{Daß}$ Altenberg die gegen seine ästhetischen Bestrebungen gerichtete Tendenz des Essays seines jüngeren Kollegen aufmerksam registriert hat, belegt eine maliziöse Bemerkung anläßlich einer Besprechung von Hofmannsthals Buch Theater in Versen (1899): "Der Autor dieser Sachen, der tiefe Dichter von wunderbaren Gedichten, hat einmal in einem sehr schönen Essay über einen Neuenr geschrieben: sMerkwürdig, so tiefe Dinge von einem, der kein Genie istk Jetzt könnte man über ihn sagen, Merkwürdig, so flache Dinge von einem, der ein Genie istllu Robert Werba: Ein Außenseiter der Theaterkritik. Peter Altenberg und das Wiener Theaterjahr 1898-99. In: Maske und Kothurn 20 (1974), S. 181. 
jungen Schriftstellers doch eine nicht zu unterschätzende Rolle. Gerade ihr experimenteller Charakter, ${ }^{64}$ der sie letztlich nur zu einem Durchgangsstadium auf dem Weg hin zu anderen Ausdrucksformen werden ließ, qualifizierte sie in besonderer Weise zum - wenn auch temporären - Vehikel ästhetischer Selbstverortung. Schon die schiere Existenz dieses Gattungskonzepts stellte für die Autoren der neunziger Jahre einen nicht zu unterschätzenden Einflußfaktor für die eigene literarische Produktion dar, weil mit seinem allgemeinen Bekanntwerden ${ }^{65}$ eine zusätzliche, bisher nicht dagewesene Gestaltungsoption existierte, die entweder ergriffen oder verworfen werden mußte. Der Qual der Wahl verstärkt ausgesetzt waren dabei Neulinge auf dem literarischen Markt wie Hofmannsthal, weil sie in ihren Gattungspräferenzen noch nicht festgelegt waren und man von ihnen in besonderem Maße die Erprobung neuer Textformen erwartete. Die Entscheidung für oder gegen ein bestimmtes Genre kam dabei einem Vabanque-Spiel gleich. Einerseits boten neue und noch unverbrauchte Gattungsmodelle die willkommene Gelegenheit, sich wirkungsvoll zu profilieren und so rasch jenes ssymbolische Kapitak zu erwerben, auf das gerade junge Autoren, die sich im literarischen Feld erst eine eigene Position erobern mußten, dringend angewiesen waren. Andererseits trafen neuartige Textsorten immer auf eine noch unvorbereitete Leserschaft, so daß ihr kommunikatives Potential schwer einschätzbar war. Zudem bestand die Gefahr, daß der mit dem Vorreiterbonus verbundene Distinktionsgewinn sich für den betreffenden Schriftsteller in kurzer Zeit in sein Gegenteil verkehrte, wenn es der Gattung nicht gelang, sich dauerhaft in dem von ihm angestrebten Segment literarischer Produktion zu etablieren.

Eindeutig für das Prosagedicht sprach die Tatsache, daß es sich dabei um ein Genre handelte, das in Frankreich bereits eingeführt war und damit ein gleichsam nachholendes Anknüpfen an internationale Tendenzen der Literaturentwicklung erlaubte. Dieser Vorteil wurde jedoch dadurch wieder geschmälert, wenn nicht gar zunichte gemacht, daß in Österreich Prosaformen einen traditionell überaus schwierigen Stand hatten. Während in Deutschland der Naturalismus für eine breite Akzep-

64 Schon Köwer meint, »daß Hofmannsthal die Gattung für sich in erster Linie als ein Experimentierfeld [...] angesehen hat«; Irene Köwer: Peter Altenberg als Autor der literarischen Kleinform. Untersuchungen zu seinem Werk unter gattungstypologischem Aspekt, S. 163. Und auch Wunberg äußert die Vermutung, daß das Prosagedicht dem Autor moffensichtlich [...] als willkommene Möglichkeit zu bestimmten Experimenten gedient zu haben scheintw; Gotthart Wunberg: 》Ohne Rücksicht auf Inhalt - lauter Venerabiliar. Überlegungen zu den Prosagedichten Hugo von Hofmannsthals, S. 323. In einem Brief an Carl August Klein vom 10. Oktober 1892 weist Hofmannsthal selbst darauf hin, daß seine »Prosa eigentümlich unruhig, unfertig, noch nicht richw sei; Briefwechsel zwischen George und Hofmannsthal, S. 45.

$65 \mathrm{Da}$ mim gängigen deutschsprachigen Gattungsspektrum die Form des Prosagedichts noch kurz vor der Jahrhundertwende« weitgehend »unbekannt« gewesen sei, wie Köwer meint, trifft in keiner Weise zu; Irene Köwer: Peter Altenberg als Autor der literarischen Kleinform. Untersuchungen zu seinem Werk unter gattungstypologischem Aspekt, S. 98. 
tanz auch und gerade kürzerer Prosa gesorgt hatte und die Anhänger gegennaturalistischer Strömungen im Rückgriff auf die eigene Lyriktradition eine sPoetisierung، der Prosa betreiben konnten, schienen im südlichen Nachbarland die Voraussetzungen für eine erfolgreiche Etablierung des Prosagedichts ausgesprochen ungünstig zu sein. Die nachrückenden Schriftsteller mußten deshalb jeweils genau abwägen, ob bzw. wie lange sie von der Nutzung eines vornehmlich soziale Distinktionsgewinne einbringenden Genres profitieren wollten und wann spätestens es ratsam war, die eigene Produktion vermehrt oder zur Gänze auf stärker normkompatible Gestaltungsmuster umzustellen. Jedenfalls erklärt sich aus dem besonderen symbolischen Status des Prosagedichts und dem konkreten zeitlichen Index seiner Rezeption, weshalb es im deutschen Sprachraum - anders als in den Nachbarländern Frankreich und Rußland - vornehmlich und von Beginn seiner Indienstnahme an als Gattung literarischer Debütanten fungierte. Ob Liliencron, Bierbaum, Croissant-Rust, Dauthendey, Hofmannsthal oder Altenberg - alle diese Autoren griffen das Textmodell auf, weil es den Reiz des Unbekannten und Innovativen, zudem Fremdartigen hatte und sich deshalb in besonderer Weise dazu eignete, beim Publikum Aufmerksamkeit zu erregen. Durch seinen, bestehende Genreregeln verletzenden, transgressiven Charakter empfahl es sich darüber hinaus als Modernitätsnachweis, der zum einen half, die junge Generation von der älteren erkennbar abzuheben, und zum anderen der gezielten Selbstprofilierung in einem dichten Feld von Konkurrenten diente.

$\mathrm{Da}$ das Prosagedicht für Hofmannsthal schon bald nur noch eine negative Bezugsgröße bildete, hängt zentral mit der stark konservativen ästhetischen Ausrichtung des Literatursystems in Österreich zusammen. Vor dem Hintergund dieser Tradition entschied sich der Autor schon zu einem sehr frühen Zeitpunkt seiner schriftstellerischen Laufbahn dafür, auf formsprengende oder -auflösende Textstrategien zu verzichten und statt dessen die literarischen Ausdrucksmöglichkeiten innerhalb des Spektrums anerkannter Gattungen zu erweitern. Das Prosagedicht diente ihm dabei als willkommenes Abgrenzungsobjekt, auf das all jene Auflösungstendenzen projiziert werden konnten, gegen die er sich mit aller Vehemenz stemmte. ${ }^{66}$ Die in diesem Zusammenhang mobilisierten Energien trugen entscheidend dazu bei, daß sich sein weiteres literarisches Schaffen zunächst konsequent in Richtung Formbewußtsein verlagerte, aber nicht einfach in einem fragwürdigen Klassizismus stekkenblieb, sondern schließlich immer stärker auf soziale Verbindlichkeit hin ausgerichtet wurde. ${ }^{67} \mathrm{Ab}$ einem bestimmten Zeitpunkt erwies sich so selbst die Lyrik als

Go Es ist in diesem Zusammenhang daran zu erinnern, daß Hofmannsthal unmittelbar nach seiner Abwendung vom Genre Prosagedicht die Absicht hegte, "Erzählungen in Versen [zu] schreiben", und hierfür ein geeignetes "Metrum suchen" (H-GW X, S. 377) wollte.

67 Foldenauer bemerkt zu recht: „Die Hinwendung zur Prosa steht bei Hofmannsthal in engstem Zusammenhang mit seinen Bemühungen um die ,Verknüpfung mit dem Lebenk und dem ,Weg ins Sozialer. Das ethische und das kommunikative Moment bedingen sich hier gegenseitig.« Karl Foldenauer: Hugo von Hofmannsthals Idee der Prosa. In: Roland Jost/ 
latent solipsistischer Gestaltungsmodus dichterischen Sprechens, ${ }^{68}$ von dem es Abschied zu nehmen galt - ein Schritt, den der Autor bereits im Jahr 1899 und damit im Alter von 25 Jahren vollzog. ${ }^{69}$

Der Fall Hofmannsthal verdeutlicht beispielhaft, wie das Prosagedicht unter Umständen selbst bei Schriftstellern der Jahrhundertwende, die nach außen hin nicht mit entsprechenden Texten hervorgetreten sind, doch als - positiver oder negativer Bezugspunkt im Schreibprozeß fungiert, deren Genrepräferenzen z.T. nachhaltig beeinflußt und somit literarische Gestaltungsentscheidungen mitbestimmt. Bezogen auf die innereuropäische Verbreitung des Textmodells führt er vor Augen, daß sich die österreichischen Autoren auf Grund des intensiven Kulturtransfers mit Frankreich erheblich früher als ihre deutschen Kollegen einen Zugang zum von Baudelaire geprägten Archetyp der Gattung verschaffen und damit eine historisch neue Phase der Entwicklungsgeschichte einleiten konnten. Waren bislang einzig Turgenevs Gedichte in Prosa mögliches Vorbild, so standen nunmehr auch die Vorgängertexte Baudelaires und Huysmans' in $\dot{A}$ rebours entwickelte Deutungsvariante als Anknüpfungspunkte zur Verfügung. Mit dieser Verbreiterung der Rezeptionsgrundlage eröffnet sich in der Historie des Prosagedichts erstmals außerhalb Frankreichs die Möglichkeit, direkt an die Genreentwicklung im Mutterland anzuknüpfen.

Hansgeorg Schmidt-Bergmann (Hrsg.): Im Dialog mit der Modeme. Zur deutschsprachigen Literatur von der Gründerzeit bis zur Gegenwart. Jacob Steiner zum sechzigsten Geburtstag. Frankfurt a.M.: Athenäum 1986, S. 70. Schon in seinen tagebuchartigen Aufzeichnungen vom Frühjahr 1893 hatte Hofmannsthal zu dem Stichwort "Ästhetismus" die Überzeugung notiert: „Die Grundlage des Ästhetischen ist Sittlichkeit.“ (H-GW X, S. 362) Und in einem Brief von Mai oder Juni 1894 an Elsa Bruckmann-Cantacuzène deutet der Autor seine literarische Entwicklung als Versuch, won dem etwas leeren Ästhetismus ins Menschlich-Sittliche hinüberzulenken«; Hugo von Hofmannsthal: Briefe 1890-1901, S. 103.

68

"Auflösung der Seele in tausend Einzeln-sensationen. Das Gemüt rettet sich in die Lyrik (Symbolismus)« (H-GW X, S. 379) heißt es unverhohlen skeptisch bereits in einer Tagebuchnotiz aus dem Jahr 1894. Zur Entwicklung und zum Stellenwert der Lyrik in Hofmannsthals Guvre vgl. Walter Perl: Das lyrische Jugendwerk Hugo von Hofmannsthals. Berlin: Emil Ebering 1936 (= Germanische Studien 173), Franz Norbert Mennemeier: Die Gedichte Hugo von Hofmannsthals. Diss. Münster 1948, Wemer Denungs: Form und Weltbild der Gedichte Hugo von Hofmannsthals in ihrer Entwicklung. Zürich: Juris 1960, und Andreas Thomasberger: Verwandlungen in Hofmannsthals Lyrik. Zur sprachlichen Bedeutung von Genese und Gestalt. Tübingen: Niemeyer 1994 (= Untersuchungen zur deutschen Literaturgeschichte 70).

69 Bewahrt bzw. im hegelschen Sinne raufgehoben wird die Lyrik dann im Drama, jenem Gattungstyp, der für Hofmannsthal Poetizität, Wirklichkeitsnähe und Publikumsbezug ineins gewährleistete. Gegenüber der Lyrik erscheint das Drama klar als die mweniger subjektiv bezogene, sozialere Literaturform«; Helmut Koopmann: Entgrenzung. Zu einem literarischen Phänomen um 1900, S. 87. 
b. Reduktive Ästhetik im Dienst der Lebensreform: Peter Altenbergs Kurzprosa

Wahrend Hofmannsthal zwar eine Reihe von Prosagedichten konzipiert und verfaßt hat, mit seinen Texten aber nicht öffentlich sichtbar hervorgetreten ist, avancierte die Gattung bei seinem Kollegen Peter Altenberg (1859-1919) zur bevorzugten Ausdrucksform und wurde schließlich sogar so etwas wie dessen ästhetisches Markenzeichen. ${ }^{70}$ Bereits die erste Buchpublikation Wie ich es sebe (1896), die von vielen Zeitgenossen als ein literarisches Ereignis besonderer Art angesehen wurde, machte den Autor in Deutschland und Österreich schlagartig bekannt. ${ }^{71}$ Anders aber als die Schriftsteller aus dem Umkreis der Münchner Moderne legte Altenberg keine Mischpublikation von Texten in sgebundener und sungebundener Rede mehr vor, sondern präsentierte ausschließlich Kurzprosa. ${ }^{72}$

Die Zuweisung der Texte zum Genre poème en prose erfolgte in erster Linie paratextuell. In der ersten Auflage geschah dies noch zurückhaltend und reichlich unentschieden, war dem Buch dort doch nur der Ausspruch »Mon verre n'est pas grand - - / - mais je bois dans mon verre. programmatisches Bekenntnis zur literarischen Kleinform gewertet werden kann, die Texte aber nicht wirklich in einer Gattungstradition verankert. Vergleichbares gilt für die Wahl des Begriffs »Skizze«, den Altenberg zur Kennzeichnung seiner Prosastücke verwendete. Einzig die Nennung von Huysmans' Roman $\dot{A}$ rebours (Ws, S. 173) deutete ebenso abstrakt wie vage auf einen zentralen Bezugspunkt der Texte hin. ${ }^{73}$ Die 1898 erschienene zweite Auflage von Wie ich es sebe dann beendete die Unsicherheit in der Gattungszuordnung ein für allemal und wies den Band klar als Sammlung von Prosagedichten aus. Das aus dem Erstdruck übernommene - nur ergänzend mit den relativ leicht entschlüsselbaren Initialen »A. de M.« versehene -

70 Schweiger errechnet insgesamt meinen Gesamtumfang von etwa 3000 Skizzen, von denen annähernd 700 in Zeitungen, Zeitschriften, Sammelwerken und Almanachen veröffentlicht wurden«; Peter Altenberg: Gesammelte Werke in fünf [davon erschienen: zwei] Bänden. Hrsg. von Werner J. Schweiger. Bd. 1: Expedition in den Alltag. Gesammelte Skizzen 1895-1898. Wien: Löcker / Frankfurt a.M.: S. Fischer 1987, S. 375.

Siehe Burkhard Spinnen: Die Seele in der Kritik. Zur zeitgenössischen Rezeption Peter Altenbergs. Magisterarbeit (Masch.). Münster 1983, sowie Andrew W. Barker: »Ein Lichtbringer und Leuchtender, ein Dichter und Prophetw. Responses to Peter Altenberg in tum-ofcentury Vienna. In: Modem Austrian Literature 22 (1989), Heft 3/4, S. 1-14.

Nienhaus' - ohnehin mißverständlich formulierte - Behauptung, es handele sich bei Wit ich es sehe um die serste deutsche Prosagedicht-Anthologies, trifft freilich nicht zu; Stefan Nienhaus: Das Prosagedicht im Wien der Jahrhundertwende. Altenberg - Hofmannsthal - Polgar, S. 31. Diese Initiatorrolle kommt nicht Altenberg, sondem bezeichnenderweise einem poeta minor, nämlich Otto Kemmer, zu; vgl. Kapitel III/8. man des belgischen Autors, zitiert (vgl. Ws, S. 229). 
Eingangszitat ${ }^{74}$ auf dem Titelblatt wurde nun durch zwei neue, auf einem gesonderten Blatt gedruckte Motti ergänzt. Das sehr umfangreiche erste stammt aus $\dot{A}$ rebours ${ }^{75}$ und führt - gleichfalls in französischer Sprache - die einschlägige Stelle aus dem 14. Kapitel über die besonderen Qualitäten des poème en prose an. ${ }^{76}$ Die eigentliche Pointe besteht freilich darin, daß Altenberg den Ausgangstext nicht unverändert läßt, sondern mehrere aufschlußreiche Veränderungen an seiner Vorlage vornimmt, was freilich ein deutschsprachiger Leser nur dann feststellen konnte, wenn er das Original zur Hand hatte:

[...] Altenberg manipule sa citation, la raccourcit considérablement et en change la présentation typographique. Il coupe le texte en paragraphes relativements courts ou, si l'on veut, en laisses ou quasi-strophes. De plus il s'arrange pour que les noms de Baudelaire et de Mallarmé ne soient plus prononcées. Autrement dit: si d'une part Altenberg se réclame (ou feint de se réclamer) de la tradition française du poème en prose il prétend d'autre part se servir de cette forme empruntée d'une façon originale, sans commettre de plagiat et sans s'inféoder à un maître, pour réputé qu'il soit. ${ }^{77}$

Wohl am deutlichsten kommt dieser Wille zur Eigenständigkeit dadurch zum Ausdruck, daß der österreichische Autor seine Vorlage an einer Stelle ergänzt. Indem er das Prosagedicht, Huysmans damit in einem wichtigen Punkt korrigierend, zusätzlich als sl'art bavard réduit en sobre silence, la mer de la prose réduite en une goutte de poésie« (Ws, S. VIII) charakterisiert, rückt er es in doppelter Weise von den ge-

74 Es ist der Widmung von Alfred de Mussets La Coupe et les lîres (1832) entnommen, die sich - wie die von Altenberg unterdrückte erste Texthälfte zeigt - gegen das Plagiieren bekannter künstlerischer Muster richtet. Eine angemessene Kontextualisierung dieses Zitats wurde von Bauer vorgenommen; vgl. Roger Bauer: Le poème en prose autrichien: de Baudelaire à Peter Altenberg.

75 Es dürfte vor allem die antibürgerliche Haltung des Protagonisten gewesen sein, die Altenberg an Huysmans' Roman angezogen hat. Koppen bemerkt über des Esseintes: „Er ist die verköprerte Negation aller bürgerlichen Ideale: sein Ästhetizismus und seine esoterische Geistigkeit erklären sich nicht aus privaten Marotten oder persönlichen Neigungen, sondem sind als Komplementärhaltung zum bürgerlichen Utilitarismus und zur Kommerzialisierung der Kunst und des Geistes zu verstehen.« Erwin Koppen: Dekadenter Wagnerismus. Studien zur europäischen Literatur des Fin de siècle, S. 39.

76 Nach Barker hat Altenberg damit meine pseudo-theoretische Kontextualisierung für seine Prosagedichte geliefert،; Andrew Barker: Telegrammstil der Seele. Peter Altenberg - Eine Biographie [1996]. [Übersetzung: Marie-Therese Pitner.] Wien/Köln/Weimar: Böhlau 1998 (= Literatur und Leben 53), S. 153.

77 Roger Bauer: Le poème en prose autrichien: de Baudelaire à Peter Altenberg, S. 243. Auf die Tatsache, wa $\beta$ in Altenbergs Motto die Namen Baudelaire und Mallarmé herausretuschiert wurden und daß der Text hier einen Wortlaut bekommt, der die Betrachtungen Huysmans' eigenwillig zusammenziehtu, hat schon Schäfer hingewiesen; Hans Dieter Schäfer: Peter Altenberg und die Wiener "Belle Epoque«. In: Peter Altenberg: Sonnenuntergang im Prater. Fünfundfünfzig Prosastücke. Auswahl und Nachwort H.D. S. Stuttgart: Reclam 1968 (= Reclams Universal-Bibliothek 8560), S. 83. 
wöhnlich der Prosa zugeschriebenen Eigenschaften ab und betont seine Zugehörigkeit zum exklusiven Ausdrucksmodus der Poesiec. ${ }^{78}$

Wie sehr Altenberg entschlossen war, das vorgefundene Gattungsmodell seinen eigenen ästhetischen Vorstellungen anzupassen, verdeutlicht auch das zweite Motto des Bandes, eine Selbstcharakteristik des Autors mit der Überschrift „Un mot de monsieur P. A. sur monsieur P. A.«, die den Fokus von der Textsorte weg auf die Person des Verfassers lenkt: "Il avait la chance de n'être ni poète lyrique ni romancier ni philosophe. De là cette union littéraire et unique de trois talens qu'on n'a pas! (Ws, S. VIII) ${ }^{79}$ Mit diesem ironischen Selbstlob brachte Altenberg seine Vorbehalte gegenüber der fortgeschrittenen funktionalen Ausdifferenzierung literarischer Gestaltungskonventionen zum Ausdruck. Auch wenn die sich selbst zugeschriebene Eigenart, kein auf ein bestimmtes Genre festgelegter Textproduzent zu sein, zunächst die Aussicht zu eröffnen scheint, die traditionelle Trennung der in einzelne Gattungen zersplitterten Ausdrucksformen zu überwinden und damit bislang getrennte Bereiche literarischer Kommunikation zu einer neuen Einheit zu verschmelzen, enttäuscht er das sich daran heftende Utopiebegehren doch umgehend mit dem Hinweis darauf, daß das konstatierte Nichtfestgelegtsein faktisch einen Mangel an schriftstellerischem Talent verrate. Das Prosagedicht präsentiert sich demnach nicht als geheimnisvolles Basisgenre, das im Sinne romantischer Transzendentalpoesie alle Gestaltungsmodi in sich vereint, sondern erscheint auf Grund seiner Formlosigkeit vielmehr als geeignete Textsorte für einen Dilettanten, der auf diese Weise einen Ausweg aus seiner Unfähigkeit zu klar differenzierter literarischer Artikulation findet. Der hochambitionierte Anspruch, den Huysmans mit dem poème en prose verbindet, wird also im Grunde nur aufgerufen, um in ironischer Brechung relativiert zu werden.

Gleichwohl wurde das in $\dot{A}$ rebours aufgestellte Postulat strenggenommen überhaupt erst von Altenberg in die Tat umgesetzt. Denn Huysmans' eigene Prosagedichte, die er in den zwei Sammlungen Le Drageoir à [später: aux] ópices (1874) und Croquis

78 Nicht zuletzt dieser Umstand spricht gegen Wellerings fragwürdige, weil unhistorische Zuordnung von Altenbergs Kurzprosa zu einem vagen Texttyp »Impromptu«; vgl. Peter Wellering: Zwischen Kulturkritik und Melancholie. Peter Altenberg und die Wiener Jahrhundertwende. Stuttgart: Hans-Dieter Heinz Akademischer Verlag 1999 (= Stuttgarter Arbeiten zur Germanistik 266), S. 32-60.

79 Die griffige Definition ging rasch in das Standardrepertoire der Altenberg-Deutung ein. So schreibt etwa Stefan Zweig in seiner Besprechung von Was der Tag mir zuträgt über den Autor: "Er ist noch immer Lyriker, Philosoph und Novellist zugleich (DJW II, S. 1156). Und Friedell äußert später: »Er ist kein Lyriker, denn er hat keine Form. Er ist kein Epiker, denn er hat keine Handlung. Er ist kein Philosoph, denn er hat kein System. Egon Friedell: Ecce Poeta. [Photomechanischer Nachdruck der Ausgabe Berlin 1912.] Mit einem Vorwort von Wolfgang Lorenz. Zürich: Diogenes 1992 (= detebe 22543), S. 128. Altenberg selbst bezeichnete sich prononciert als »Genie ohne Fäbigkeitem;; Peter Altenberg. Mein Lebensabend. Berlin: S. Fischer 1919, S. 8. 
parisiens (1880) - beide blieben in Deutschland augenscheinlich unrezipiert - veröffentlicht hat, können kaum als Einlösung der zudem ja auch erst einige Jahre später erhobenen Forderung nach einem wroman concentré en quelques phrases« gelten, sondern orientieren sich im wesentlichen an den Vorgaben Baudelaires ${ }^{80}$ und dessen vermeintlichem Vorbild Bertrand. Faktisch war Altenberg der erste (und blieb im Grunde auch der einzige), der das in $\dot{A}$ rebours entworfene Programm komprimierter Narrativik zur Leitlinie seines literarischen Schaffens gemacht und so jene Textform verwirklicht hat, die bei Huysmans nur als Wunschphantasma begegnet. ${ }^{81}$

Es muß freilich in jedem Fall davon ausgegangen werden, daß der - fließend französisch sprechende - österreichische Autor auch die Prosagedichte von Baudelaire und Turgenev kannte. Auf den ersten Blick mag es sogar scheinen, als ob Altenbergs Texte insbesondere den Petits poèmes en prose nahestünden, bildet doch in ihnen häufig die Großstadt den Raum - oder zumindest den Hintergrund - der Handlung, und die Figuren und Begebenheiten, die geschildert werden, scheinen wie durch das Auge eines baudelaireschen Flaneurs gesehen. ${ }^{82}$ Doch wrepräsentiert die urbane Landschaft« für Altenberg nur bedingt weine Art Anti-Natur ${ }^{83}$, sondern stellt in erster Linie einen verdichteten Erfahrungsraum dar, in dem die Gegensätze, aber auch die Schönheiten des modernen Lebens in gesteigerter Form zum Ausdruck kommen:

80 Interessanterweise findet sich der Gedanke des Sprachkonzentrats bereits bei Baudelaire. So lautet die vorletzte Verszeile des ursprünglich als Epilog für die zweite Ausgabe der Fleurs du mal geplanten titellosen Gedichts »Tranquille comme un sage ...«, das erstmals 1887 in den CEutres posthumes veröffentlicht wurde: "Car j'ai de chaque chose extrait la quintessencer (Oc I, S. 192). Und in dem Prosagedicht Perte d'auriale wird der Dichter - freilich ironisch - als »buveur de quintessences« und als »mangeur d'ambroisie« (Oc I, S. 352) bezeichnet; Altenberg nimmt darauf in seinem Text Essay, V'ersuch Bezug, wo es heißt: "[... wir nähern uns dem Extract-Essen, Ambrosia verdenden Gottesk Peter Altenberg: Was der Tag mir zuträgt. Fünfundfünfzig neue Studien. Berlin: S. Fischer 1901, S. 241.

Den neben $\operatorname{dem} Z$ Zitat aus $\dot{A}$ rebours wohl deutlichsten Hinweis für Altenbergs Orientienung an Huysmans' stellt das Prosagedicht Roman am Lande dar, das die Forderung nach einem wroman concentré schon im Titel einlöst.

Stefan Zweig will in Altenberg gar den "Typus des Grossstadtdichters" (DJW II, S. 1156) erkennen. Köhn hat diese mißverständliche Einschätzung dahingehend präzisiert, »[...] daß die Großstadt in Altenbergs Texten nur so lange als Raum einer visuellen Erfahrung fungieren kann, wie es dem Ich gelingt, mittels seiner besonderen Optik die urbane Realität in Natur zu verwandeln oder ihr zumindest naturhafte Züge zu verleihen, die die spezifisch großstädtischen Züge in den Hintergrund treten lassen. Versagt diese Technik, zeigt sich die Unfahigkeit, die Großstadtwirklichkeit in ihren Extremen, ihrer Widersprüchlichkeit und auch Häßlichkeit wahrzunehmen, viel weniger noch zu ertragen. « Eckhardt Köhn: Stenograph des Wiener Lebens. Großstadterfahrung im Werk Peter Altenbergs. In: Sprachkunst. Beiträge zur Literaturwissenschaft 17 (1986), S. 30.

83 Eckhardt Köhn: Straßenrausch. Flanerie und kleine Form. Versuch zur Literaturgeschichte des Flaneurs bis 1933, S. 70. Gleichwohl klagt Altenberg zuweilen über die nunermeßliche Un-Natur `Großstadte; Peter Altenberg: Mein Lebensabend, S. 275. 
Tandis que chez Baudelaire la grande ville moderne est le lieu de la solitude, de la déréliction et suscite des rêves d'évasion vers une réternité de délices imaginaire, Vienne et ses environs sont chez Altenberg des endroits privilégiés où à chaque moment peut avoir lieu la parousie du Beau. ${ }^{84}$

Dementsprechend stehen bei dem österreichischen Autor ganz andere Erscheinungen im Zentrum der Aufmerksamkeit als bei Baudelaire: wa nature libre, impolluée; les êtres simples, naturels ${ }^{85}$. Und wenn man im Verhaltensrepertoire des Personals altenbergscher Texte jenem "spleen« begegnet, der die meisten Figuren der Petits poèmes en prose kennzeichnet, dann erscheint er dort gewöhnlich als Krankheitssymptom, das es zu kurieren gilt. Altenbergs gestalterischer Impetus richtet sich denn auch zentral auf die Beantwortung der Frage, wie eine adäquate Form der Lebensführung möglich ist. Insofern kann sein ästhetischer Ansatz - ebenso wie der Turgenevs - in einem grundlegenden Sinne moralistisch genannt werden. ${ }^{86}$

Die Verwandtschaft zwischen den zwei Letztgenannten zeigt sich vor allem in der z.T. unverhüllt pädagogischen Ausrichtung ihrer Texte, die in der Formulierung didaktischer Sentenzen bzw. in der aphoristischen Verkürzung von Aussagen am sichtbarsten hervortritt. Doch während Turgenev auf diese Weise die epistemologischen Täuschungen des Menschen aufzudecken sucht, um diesen - im Sinne Schopenhauers - zu einer illusionslos-pessimistischen Einsicht in die tatsächlichen Bedingungen irdischer Existenz zu bewegen, ist Altenberg vielmehr bestrebt, die Schäden moderner Zivilisation zu analysieren mit dem Ziel, negative Kultureinflüsse künftig auszuschalten bzw. zu neutralisieren und eine dauerhaft gesunde Lebensführung für jedermann zu ermöglichen. Der Umstand wiederum, daß sein Programm sich zentral auf eine Verbesserung der lebensweltlichen Existenz richtet und Kunst in erster Linie als geeignetes Mittel begreift, eine solche zu erreichen, verbindet seine ästhetischen Leitvorstellungen mit denen der Münchner Moderne. ${ }^{87}$ Hofmannsthal dürfte im übrigen nicht zuletzt deshalb so energisch gegen Altenberg Stellung bezogen haben, weil er spürte, daß dessen latent instrumentelles Verhältnis zur Kunst seinem eigenen auratischen Literaturverständnis diametral entgegenstand. Wie sehr letzterem tatsächlich an der ästhetischen Meliorisierung menschlicher Existenz lag

84 Roger Bauer: Le poème en prose autrichien: de Baudelaire à Peter Altenberg, S. $246 f$.

5 Ebd., S. 246.

86 Auch Žmegač konstatiert, daß Altenberg in seinen Texten häufig wzum strengen Moralisten wird«, Viktor Żmegač: Die Geburt der Gesundheit aus dem Geist der Utopie. Somatische Utopien bei Peter Altenberg. In: V. Ż.: Tradition und Innovation. Studien zur deutschsprachigen Literatur seit der Jahrhundertwende, S. 136. Direkter Beleg für die Affinität Altenbergs zu moralistischen Denk- und Aussagemustem ist etwa das Zitat eines Ausspruchs von La Rochefoucauld in einem seiner Werke; vgl. Peter Altenberg: "Semmering 1912«. Berlin: S. Fischer ${ }^{3} 1913$, S. 232.

87 Es kann deshalb kaum verwundern, daß Altenberg im Herbst 1899 nach München übersiedelte, wo er mit einigen Unterbrechungen bis Mai 1901 lebte. 
und wie bedenkenlos er dabei Literatur zum Vehikel der Lebenshilfe zu degradieren bereit war, geht aus seinem programmatischen Text Kunst hervor:

[...] wie ein edles Phantom bist du bisher gewesen [...], das am hellichten Alltage der Strasse vor den geschäftigen, allzu geschäftigen Leuten auftaucht! So entfemt von ihrem Alltagsdasein [...]! Ein mattes Überflüssiges, geschaffen von überflüssigen Künstlers Gnaden! Eine luxuriöse Tändelei! Wir wollen dich aber nun lebendig machen, dich dem Leben des Alltages näherrücken, du blut-, du fleischloses Gespenst Kunst! In die Stunde wollen wir dich rücken, die erlebt wird, dass du befruchtend und bereichernd wirkest auf die Alltagsmenschen!

[...]

Die Kunst ist die Kunst, das Leben ist das Leben, aber das Leben künstlerisch leben zu wollen, ist die Lebenskunst!

Wir wollen die Kunst, dieses Exzeptionelle, dem Alltage vermählen. [...] Wir wollen dich erziehen, das heisst aufhalten in deinen Rastlosigkeiten, auf dass du verweilest, schauest, staunest! Es gibt soviel zu schauen und zu staunen! Innezuhalten, zu verharren! Stillgestanden, Allzugeschäftiger! Nütze deine Augen, den Rothschildbesitz des Menschen! Wir wollen euch nur zeigen, woran ihr blindlings vorüberraset! Es gibt Menschen, die nichts zu tun haben. Vollkommen Überflüssige des Daseins. Mit weit aufgerissenen Augen schauen sie und schauen. Diese hat das Schicksal bestimmt, die Vielzuvielbeschäftigten zum Verweilen zu bringen vor den Schönheiten der Welt! (Ws, S. 293f.)

Bei Altenberg ist das Prosagedicht denn auch nicht Selbstzweck, sondern Teil eines Programms zur Lebensreform, und wird in den Dienst der Diätetik gestellt. ${ }^{88} \mathrm{Mehr}$ noch: Die von ihm propagierte Reduktion auf das Wesentliche erweist sich bei genauerem Hinsehen als dezidiert antidekadente Geste. ${ }^{89}$ Das Huysmans-Motto am Anfang von Wie ich es sebe darf deshalb auch keinesfalls als Signal einer Zustimmung zum Wertekanon der décadence gewertet werden, ${ }^{90}$ zumal Handlung, Figuren und Themen von $\dot{A}$ rebours in Altenbergs (Euvre durchweg kritisch bewertet werden. ${ }^{91}$

88 Dies bleibt Gerd-Dieter Stein verborgen; vgl. seinen reichlich redundanten Aufsatz: GerdDieter Stein: „Wie ich es sehe«: Skizze - poème en prose - Prosagedicht. Überlegungen zu Peter Altenbergs impressionistischer Prosa.

So heißt es in dem Text In München explizit: "Sehet, der neue, der moderne Künstler will Euch aber mit der Natur vereinigen« (Wz, S. 306). Altenberg kritisiert die Kunst des Historismus und des Kunstgewerbes gleichermaßen und empfiehlt statt dessen: "Stellet doch da lieber unter Glas die wirklichen Kunstwerke der Natur, wunderbare exotische Käfer oder edle Muscheln in matten Farben." (W, S. 307)

Dieses Mißverständnis unterlief freilich schon den Zeitgenossen; so bezeichnet beispielsweise Rudolf Strauß in seiner Besprechung von Wie ich es sebe Altenberg als »Dicadent par excellences (DJW I, S. 607). Bauer hat dagegen mit guten Gründen plausibel gemacht, daß Altenberg in Lebensstil und Schreibhaltung als Antipode der Dekadenz angesehen werden muß: "Altenberg a été, plus spécialement dans son programme littéraire, tout autre chose que le décadent, l'impressioniste et l'esthète fin de siècle que trop longtemps et trop souvent on a voulu voir en lui.« Roger Bauer: Le poème en prose autrichien: de Baudelaire à Peter Altenberg, S. 252.

91 Weit davon entfemt, sich ihm idenfikatorisch zu nähern, billigt Altenberg dem Werk allenfalls eine Rolle als Indikator einer weltanschaulichen Fehlentwicklung - die sgesunde Krank- 
Dex österreichische Autor bezieht zwar das Konzept einer auf das Minimum von Sprachzeichen reduzierten literarischen Darstellung von einem der Hauptvertreter der décadence, distanziert sich aber vom ästhetizistischen Kontext dieses Programms. Um die poetologische Forderung narrativer Verknappung wirkungsvoll einlösen zu können, orientiert er sich am Beispiel Turgenevs, dessen Muster einer narrativen, zur aphoristischen Aussage tendierenden Moralistik er aufgreift und unter Rückbezug auf Baudelaire für die Schilderung modernen Lebens fruchtbar macht. Auch Altenberg verarbeitet also in seiner Konzeption des Prosagedichts - ähnlich wie Hofmannsthal - insgesamt drei der als Rezeptionsgrundlage zur Verfügung stehenden intemationalen Gattungsentwürfe. ${ }^{92}$

Huysmans fungierte in diesem Kontext lediglich als willkommener Stichwortgeber. Er half dem österreichischen Autor eine reduktive Weise sprachlicher Textkonstitution zu legitimieren, die nicht mehr mit den herkömmlichen Allegorisierungsverfahren operiert. ${ }^{93}$ Anstatt wie noch Turgenev abstrakte Begriffe zu personifizieren, entwickelte Altenberg eine betont lakonische Form der Darstellung, die das Gemeinte nur andeutet:

Mit Wenigem Viel sagen, das ist es! Die weiseste Ökonomie bei tiefster Fülle, das ist auch beim Künstler Alles - - wie beim Menschen. Auch der Mensch ist ein Künstler, sollte es sein - - ein Lebens-Künstler! Die Japaner malen einen Blüthenzweig und es ist der ganze

heit einer kranken Gesundheit« - zu; insofem könnten die darin geschilderten Ausprägungsformen ästhetischen Solipsismus sogar als "Geburts-Wehen künftiger Entwicklungen« (Ws, S. 173) angesehen werden. Das Buch markiere mithin eine Art notwendiges Durchgangsstadium auf dem Weg zu einer kulturellen und gesellschaftlichen Genesung. Deutlicher wird Altenberg dann in dem Prosagedicht Ein poesischer Abend (vgl. Ws, S. 69), dessen Anfang als "Parodie einer Szene aus [...] $A$ rebours« angelegt ist: Hier distanziert er sich programmatisch vom Protagonisten des Esseintes und setzt dem "Todeskult der Hauptfigur" die "Darstellung einer Feier aus Anlaß einer neuen Lebensverbindung entgegen; Stefan Nienhaus: Das Prosagedicht im Wien der Jahrhundertwende. Altenberg - Hofmannsthal - Polgar, S. $65 f$. In De libertate andererseits, wo auf den Beginn des sechsten Kapitels von Huysmans' Roman angespielt wird, läßt Altenberg einen als »Robespierre der Seele» charakterisierten "Dichter" auftreten, dessen lebenspraktischem Nonkonformismus (mà reboursı leben«) er augenscheinlich große Sympathie entgegenbringt; vgl. Wz, S. 76. Alles in allem wird man sagen müssen, daß die Einstellung des österreichischen Autors zur décadence-Bewegung von Ambivalenz geprägt ist: Während er ihren antibürgerlichen Impetus durchaus schätzt, grenzt er sich von ihrer Morbidität, ihrer einseitigen Bevorzugung extremer Künstlichkeit und ihrem ästhetizistischen Programm erkennbar ab. Eine differenzierte Einschätzung dieses spannungsreichen Verhältnisses findet sich bei Viktor Żmegač: Die Geburt der Gesundheit aus dem Geist der Utopie. Somatische Utopien bei Peter Altenberg.

Als unergiebig, weil spekulativ und teilweise sogar irreführend, erweist sich in diesem $\mathrm{Zu}$ sammenhang der Aufsatz von Barbara Z. Schoenberg. The Influence of the French Prose Poem on Peter Altenberg. In: Modem Austrian Literature 22 (1989), Heft 3/4, S. 15-32.

Es ist deshalb verfehlt, ausgerechnet Altenberg als mmaster of modern allegory zu bezeichnen; Randolph J. Klawiter: Peter Altenberg and das junge Wien. In: Modem Austrian Literature 1 (1968), Heft 4, S. 9. 
Frühling. Bei Uns malen sie den ganzen Frühling und es ist kaum ein Blüthenzweig. Weise Ökonomie ist Alles! (Ws, S. 111f. $)^{94}$

Er folgt dabei der Überzeugung. "Was man sweise verschweigt ist künstlerischer, als was man igeschwätzig ausspricht« (Wz, S. 6), wie es in dem Band Was der Tag mir zuträgt (1901) programmatisch heißt. $\mathrm{Zu}$ diesem Zweck entwickelt Altenberg eine Gestaltungstechnik, die er selbst wdas sabgekürzte Verfabreww nennt und deren Ziel darin besteht, weinen Menschen in einem Satze [...], ein Erlebnis der Seele auf einer Seite, eine Landschaft in einem Worter (ebd.) zu schildern - gemäß der Maxime: »Weshalb soll man nicht alles in zwanzig Zeilen lieber, rascher, prompter, definitiver, radikaler, rücksichtsloser, dezidierter ausdrücken als auf zwanzig bis fünfzig Seiten?! ${ }^{95}$ Handlungszusammenhänge werden dabei bewußt fragmentiert, Figuren nur schemenhaft angedeutet, so daß der Textverlauf mehr oder weniger diskontinuierlich wirkt. Die äußerste Verknappung von im Text gegebenen Informationen lenkt die Aufmerksamkeit auf das Ungesagte, ${ }^{96}$ das auch insofern besondere Bedeutung erhält, als nonverbale Ausdrucksformen wie Mimik und Gestik vergleichsweise breiten Raum einnehmen. Zudem bricht die Rede des Textpersonals häufig ab und mündet in Schweigen - ein Umstand, dem durch eine expressive Interpunktion Rechnung getragen wird. Vor allem die »Überproduktion an Fragezeichen, Rufzeichen, Gedankenstrichen, spationierten Worten ${ }^{97}$ trägt entscheidend ${ }^{98}$ zur semantischen Aufladung der Typographie bei.

94 Schon Hofmannsthal hatte in seinem Artikel über die Ausstellung der Münchener SSezessionc und der Freien Vereinigung Düsseldorfer Künstler, (1894) »das Japanisieren « (H-GW VIII, S. 553) als jüngsten ästhetischen Trend ausgemacht. Vgl. hierzu Siegfried Wichmann: Japonismus: Ostasien - Europa. Begegnungen in der Kunst des 19. und 20. Jahrhunderts. Herrsching. Schuler 1980, sowie das Kapitel wLiterarischer japonismex in: Andrew Barker/ Leo Lensing: Peter Altenberg. Rezept die Welt zu sehen. Kritische Essays, Briefe an Karl Kraus, Dokumente zur Rezeption, Titelregister der Bücher. Wien: Braumüller 1995 (= Untersuchungen zur österreichischen Literatur des 20. Jahrhunderts 11), S. 112-121, $399 \mathrm{f}$. Zum Zusammenhang von Prosagedicht und Japonismus siehe den Abschnitt "The Birth of the Prose Poem from the Spirit of Japaneryw bei Thomas O. Beebee: The Ideology of Genre. A Comparative Study of Generic Instability. University Park (Pennsylvania): The Pennsylvaria State University Press 1994, S. 113-147.

95 Peter Altenberg. Mein Lebensabend, S. 143. Das nabgekürzle Veffabrem tendiert dabei zur Erzeugung aphoristischer Aussagen, die freilich relativ selten die für die Gattungstradition typische Gestalt einer »linguistic epiphany“ annehmen, sondern gewöhnlich in der schlichten Form einer Maxime oder einer im Verkündigungsgestus geäußerten Sentenz daherkommen; Richard T. Gray: Aphorism and Sprachkrises in Turn-of-the-Century Austria. In: Orbis Litterarum 41 (1986), S. 340. Rudolf Strauß nennt Altenberg deshalb einen »Meister der Andeutung (DJW I, S. 608). Egon Friedell: Ecce Poeta, S. 165. Als Mittel, um die Aufmerksamkeit des Lesers zu lenken, hatte erstmals Dehmel den Sperrdruck in lyrischen Texten ausgiebig verwendet. Eine Begründung für seine Vorgehensweise gibt er in dem Band Erläsungen (1891); vgl. hierzu Kapitel III/3b. Stilbildend wurde der wirkungsästhetisch begründete häufige Gebrauch der Spationierung durch Nietzsches Schriften. 
Altenbergs von Alfred Polgar als "Ausspartechnik«" charakterisierte Darstellungsweise zeichnet sich also durch eine ausgeprägte "Tendenz zur Entfabelung " ${ }^{100}$ bei paralleler Aufwertung der Druckgestalt aus. Symptomatisch für dieses Gestaltungsverfahren ist auch, daß der direkten Rede eine zentrale Rolle zukommt, was den Texten - vor allem weil Idio- und Soziolekte entsprechend sprachlich nachgebildet werden - einen dokumentarischen Charakter verleiht, so als handle es sich dabei um "Gesprächsniederschriften « ${ }^{101}$, um schriftliche Protokolle tatsächlich gewechselter Dialoge. ${ }^{102}$ Zugleich aber erscheint das Mitgeteilte hochgradig redundant (was na-

98 Köwer bemerkt zu deren Funktion: „Wollen die doppelt und dreifach gesetzten Frage- und Ausrufezeichen den Anteil emotionaler Lebensnähe initiieren, so vertreten die gehäuften Gedankenstriche, die an Maeterlinck erinnern, die Komponente des schweigens: Sie lassen die Sätze ins nicht mehr Formulierte und Formulierbare, ins Ungewisse und Unendliche ausklingen und führen die vom Leser zu erschließenden, zur Textbotschaft führenden Gedankenlücken auch sichtbar vor Augen. [...] Es ergibt sich ein 'Sehtext, in dem das zeichenhaft vermittelte Nonverbale eine nun auch raummäßig gleichberechtigte Stellung einnimmt.« Irene Köwer: Peter Altenberg als Autor der literarischen Kleinform. Untersuchungen zu seinem Werk unter gattungstypologischem Aspekt, S. 140f.

Alfred Polgar: Peter Altenberg. In: Peter Altenberg. Der Nachlaß. Berlin: S. Fischer 1925, S. 151. Die Altenberg-Forschung hat diesen Terminus dann übemommen. Vgl. etwa Peter Wagner: Peter Altenbergs Prosadichtung. Untersuchungen zur Thematik und Struktur des Frühwerks. Diss. (Masch.) Münster 1965. Der Begriff der »Ausspartechnik» läßt sich in mancher Hinsicht in fruchtbaren Zusammenhang mit Isers rezeptionsästhetischem Konzept der "Leerstelle« bringen; vgl. Wolfgang Iser: Der Akt des Lesens. Theorie ästhetischer Wirkung, S. 257-355.

${ }^{100}$ Iris Paetzke: Erzählen in der Wiener Moderne. Tübingen: Francke 1992 (= Edition Orpheus 7), S. 9. Paetzke schreibt diese Tendenz der gesamten Prosa der Wiener Modeme zu, unterstreicht aber zu Recht: "Die Form, in der diese Entwicklung ihren extremen Ausdruck findet, ist das Prosagedicht, das vollkommen auf die Handlungsführung verzichten kanne; ebd. "Für die Wiener Moderne sind in dem Zusammenhang vor allem die frühen Sammlungen Peter Altenbergs zu nennen«; ebd., S. 10.

101 Eckhardt Köhn: Stenograph des Wiener Lebens. Großstadterfahrung im Werk Peter Altenbergs, S. 34.

102 Überhaupt fällt auf, daß Altenberg sich gem einschlägiger Metaphem aus dem Kontext naturalistischer Ästhetik bedient. Doch auch wenn er sich wiederholt mit einem Spiegel vergleicht - "Ein Spiegel sein der Dinge wm sich her/" (W, S. VII) heißt es programmatisch in den Mottoversen von Was der Tag mir zuträgt - und seine Darstellungstechnik als photographische bezeichnet - „Moment-Photographen wollen wir werdenu; zitiert nach: Andrew Barker: Telegrammstil der Seele. Peter Altenberg - Eine Biographie, S. 67 -, geht es bei ihm weniger um ein mimetisches Literaturkonzept, vielmehr dient Nachahmung lediglich als Leitbegriff, um ein künstlerisches Konzept zu verteidigen, das die Ungeschiedenheit von Literatur und Leben reklamiert, die sich im übrigen auch in Altenbergs ästhetischer »Organisation der Wahrnehmungu zeigt; Eckhart Köhn: Stenograph des Wiener Lebens. Großstadterfahrung im Werk Peter Altenbergs, S. 27. Barker spricht denn auch von Altenbergs wquasinaturalistischer Ästhetikc; Andrew Barker: Telegrammstil der Seele. Peter Altenberg - Eine Biographie, S. 170. Der österreichische Autor bedient sich also der naturalistischen Darstellungstechniken, um endlich Kunst und Natur zur Deckung zu bringen und das von 
türlich abermals die Suggestion von Authentizität erhöht): Die Figuren reden zwar ständig, erreichen dadurch aber gerade keine Verständigung. Entweder verbergen sie, was sie bewegt, hinter den vorgestanzten Formeln gesellschaftlich normierter Konversation oder sie geraten an die Grenzen der Artikulationsfähigkeit, weil sich die Sprache als ungeeignet erweist, um dem Gemeinten Ausdruck zu verleihen. Worum es in den Texten reigentlich، geht, läßt sich kaum mehr dem diskursiv Mitgeteilten entnehmen, sondern kann nur in einem komplexen Verfahren entschlüsselt werden, bei dem die Gesamtheit der Textsignale Berücksichtigung findet.

Ein derartiges ästhetisches Verfahren ist natürlich besonders zur Gestaltung psychischer Vorgänge geeignet, die sich der Sichtbarkeit entziehen, weil sie sich im Inneren einer Person abspielen und dieser selbst möglicherweise gar nicht oder nur teilweise bewußt sind. Altenberg hat seine Darstellungstechnik deshalb auch als " $T e$ legramm-Stil der Seelex $\left(\mathrm{W}_{\mathrm{z}}, \mathrm{S} .6\right)$ bezeichnet, was einmal mehr auf das besondere Interesse der Wiener Moderne am Subjekt verweist. ${ }^{103}$ Was sie im Kontext der Verschiebungen innerhalb des Gattungsystems um 1900 besonders interessant macht, ist der Umstand, daß die Zurückdrängung der Narration einerseits mit einer $\mathrm{Zu}$ nahme szenisch-performativer Textanteile einhergeht, was die Texte zumindest ein Stück weit dem Drama annähert. ${ }^{104}$ Andererseits - und das ist im hier erörterten Zusammenhang von größerer Bedeutung - nimmt Altenbergs äußerst verknappte Kurzprosa mit ihrer weitgehenden Eliminierung des plots und der ins Chiffrenhafte

Holz in seiner berühmten Gleichung eingesetzte w $x$ serschwinden zu lassen. Daß Altenberg realiter freilich höchst konstruktivistisch mit der ihn umgebenden Realität umgeht, verdeutlicht unmißverständlich ein Text wie Das Erlebnis; vgl. Peter Altenberg. Nachfechsung. Berlin: S. Fischer 1916, S. 60f.

${ }^{103}$ Vgl. Jacques Le Rider: Das Ende der Illusion. Die Wiener Modeme und die Krisen der Identität, und Michael Worbs: Nervenkunst. Literatur und Psychoanalyse im Wien der Jahrhundertwende. Frankfurt a.M.: Europäische Verlagsanstalt 1983. Punktuell zeigen sich hier sicher Gemeinsamkeiten mit der Prosa Schnitzlers, wobei es Altenberg - anders als diesem - nicht darum geht, die psychische Innenwelt narrativ abzubilden bzw. mit den Mitteln der Narration zu simulieren.

${ }^{104}$ Formal etwas ganz ähnliches wie in seinen Prosagedichten versuchte Altenberg später mit seinen »Fünf-Minuten-Szenen«, Kürzestdramen, die mit ihrem z.T. hohen Anteil von ausführlichen, ins Narrative tendierenden Bühnenanweisungen an die Prosaexperimente von Arno Holz und Johannes Schlaf eninnem. Der Autor bediente sich dieser Textsorte in insgesamt drei seiner Buchveröffentlichungen - Märchen des Lebens (1908), Bilderbögen des kleines Lebens (1909) sowie Neues Alies (1911) - und stellte sie funktional in den gleichen ästhetischen Kontext wie seine Kurzprosa. In einem Zeitschriftenabdruck eines dieser Stücke wird das Genre folgendermaßen charakterisiert: "Extrakte ion Ereignissen! Der Zuschauer wirkt mit, indem er ergänzt. In ihm erst wird es zu einem Ganzen. Er wird geehrt, indem man ihn selbst zum Dramatiker erhöht.« Zitiert nach: Andrew Barker: Telegrammstil der Seele. Peter Altenberg - Eine Biographie, S. 70. Altenberg knüpft hier unmittelbar an seine in Wie ich es sebe erstmals angewandte und in Was der Tag mir zuträgt dann poetologisch explizierte Extrakttheorie an, deren Ziel es ist, die Kunst in den unmittelbaren Lebensvollzug einzubetten. 
getriebenen Aussage deutlich Ausdrucksqualitäten der Lyrik an. ${ }^{105}$ Die Wahl der kurzen Prosa als Ausdrucksmedium resultiert im wesentlichen aus der Tatsache, daß es sich dabei um ungebundene Rede sunterhalbr der gängigen Genrekonventionen handelt. Eine kompakte Darstellungsweise soll in diesem Zusammenhang dem Schriftsteller die Möglichkeit geben, jenen Grad an sprachlicher Verdichtung zu erreichen, der gemeinhin nur der Lyrik zugebilligt wird, die selbst keine wirklich sfreier sprachliche Gestaltung zuläßt. Da man Gedichten [...] Vers und Reim binderlichu seien, folgert Altenberg in Übereinstimmung mit den Theoretikern des Naturalismus kurzerhand: "Also mache man schöne, tiefe Gedichte obne diese Anstrengungen ${ }^{106}$.

Die Zeitgenossen haben seine ästhetische Selbstverortung meist übernommen, was sich besonders daran zeigt, daß sie die optisch klar als Prosa ausgewiesenen Texte des österreichischen Autors im allgemeinen der Lyrik zurechneten. Franz Servaes etwa zeigt sich in seinem Aufsatz Impressionistische Lyrik überzeugt, daß Altenbergs literarische Produktion, wobwohl sich als Prosa gebend, [...] in das Reich der neueren impressionistischen Lyrik hinüber« (MD-J, S. 39) deute. Egon Friedell schlägt als Bezeichnung für dessen Texte die Bezeichnung wlyrische Prosagedichte ${ }^{107}$ vor. Otto Stoessl meint, der Autor habe die Leser min manchen Skizzen so selig gemacht [...], wie nur ein ganz echter, erhabener Dichter die Menschen beglücken kann« (DJW II, S. 772f.). Und selbst für Rudolf Kassner steht angesichts von Altenbergs Kurzprosa fest: »Es ist Dichtung im reinen und neuen Sinne. ${ }^{108}$ So kam es zu der selbst für die Jahrhundertwende einmaligen Situation, daß ein Autor, der sein ganzes Leben lang nicht (oder nur ganz am Rande) mit Versgedichten hervorgetre-

${ }^{105}$ Köwer hat zu Recht darauf hingewiesen, daß Altenberg zuweilen whythmisch-lautliche Elemente und teilweise sogar Endreime in die Prosasprache" einbettet: „Nahezu jeder Text des Frühwerks verfügt über einzelne, meist am Textanfang oder -ende, also an zentraler Stelle plazierte, thythmisch durchgeformte Abschnitte oder Schlußwendungen von Abschnitten. Sie sind fast immer auf die Aussagen des Erzählers beschränkt, treten also kaum in dialogischen Passagen auf, in denen Altenberg der gesprochenen Sprache gerecht werden will." Irene Köwer: Peter Altenberg als Autor der literarischen Kleinform. Untersuchungen zu seinem Werk unter gattungstypologischem Aspekt, S. 132.

${ }^{106}$ Peter Altenberg. Mein Lebensabend, S. 143. Ganz ähnlich heißt es in Fechsung. "Tiefe Gedichte obne Reim und Versmaß sind noch besser als solche mit. Denn bei ihnen spürt man das Restlose, während man bei den anderen stets noch meint, wie tief sie erst geworden wären obne das Prokrustesbett, die ,Eiserne Jungfrauk von Vers und Reim! Peter Altenberg: Fechsung. Berlin: S. Fischer 1915, S. 263f. Die Formulierung wobre Reim und Versmaßu dürfte dabei eine direkte Reminiszenz an Baudelaires Widmungsvorrede "à Arsène Houssaye« darstellen, wo er an seinen Petits poimes en prose hervorhebt, daß sie "sans rythme et sans rimer (Oc I, S. 276) seien. Der in Altenbergs Poetik nicht sehr virulente, in der Gattungstradition des Prosagedichts aber bedeutsame implizite Bezug auf die Lyrik findet seinen Widerhall darin, daß gelegentlich Versgedichte in die Textsammlungen integriert werden.

107 Egon Friedell: Ecce Poeta, S. 151. Auch spricht er von "Prosalyrik«; ebd., S. 125.

${ }^{108}$ Rudolf Kassner: Sämtliche Werke. Im Auftrag der Rudolf Kassner Gesellschaft hrsg. von Emst Zinn. Bd. 2. Pfullingen: Neske 1974, S. 406 
ten ist, ${ }^{109}$ dennoch weithin als Lyriker ${ }^{110}$ galt und im allgemeinen das Prädikat sDichter zugesprochen erhielt. ${ }^{111}$

Diese Identifizierung geschah natürlich nicht zufällig. Neben dem stark auf psychische Prozesse ausgerichteten Darstellungsfokus der Texte, ihrer Handlungsarmut und der Vorliebe für gemeinhin als spoetischı angesehene Situationen war es vor allem die für Altenbergs Frühwerk charakteristische Bildung personell, topographisch oder thematisch miteinander verbundener Textensembles, welche die indirekte Bindung seiner Kurzprosa an die Versdichtung illustrierte. Der Autor übertrug damit das im Rahmen der Lyrik vertraute Verfahren der Zyklusbildung auf die Prosa - eine Technik, die in dieser Form gänzlich neu war und auch im französischen Gattungskontext keine Vorläufer hat. Er nannte die so entstehenden Gebilde freilich nicht Zyklus, sondern bezeichnete sie in Abgrenzung vom lyrischen Sprachgebrauch und unter Rückgriff auf die ästhetische Terminologie des Naturalismus als "SkizzenReihen «. ${ }^{112}$ Die beiden ersten Buchveröffentlichungen werden von dieser Darstellungsweise geradezu dominiert: So hat Altenberg in Wie ich es sebe einmal 22, einmal 19 und einmal 17 Texte zu den drei Textgruppen "See-Ufer«, "Frau Bankdirektor

${ }^{109}$ Einige wenige Versgedichte finden sich zwar verstreut in Altenbergs Textsammlungen, entfalten dort aber zu keinem Zeitpunkt die Kraft eines Gegenpols zur Prosa wie bei Bierbaum, Croissant-Rust oder Dauthendey. Die zeitgenössischen Kritiken gehen denn auch auf diese qquantité négligeablex, die zudem auch qualitativ gegenüber den Prosagedichten abfallt, nicht weiter ein. Dennoch zeigen Altenbergs vereinzelte lyrische Texte, daß ihm die in diesem Zusammenhang angestellten typographischen Experimente mit dem Gattungsstatus durchaus vertraut waren. So verzichtet er - ganz wie Richard Dehmel oder Anna Croissant-Rust - im allgemeinen konsequent auf den Einsatz der Versmajuskel und rückt die jeweils erste Zeile eines Abschnitts zudem meist wie bei Prosatexten üblich ein.

110 Altenberg selbst freilich war über derartige Zuschreibungen wenig erbaut. So beschwert er sich in einem Brief an Samuel Fischer vom 15. Februar 1915 bitter über den Freund Karl Kraus, der ihn, »den größten tiefsten weisesten und zugleich einfachsten Neuerer aller modemen Lebens-Anschausungen[] zu einem großen Lyriker und feinen Stimmungsmaler à la Lilienkron binauf degradierzu habe; zitiert nach: Andrew Barker. Telegrammstil der Seele, S. 281.

111 Dies belegt nicht zuletzt die - üblicherweise sich nur auf Versdichtungen richtende - Vertonung einiger seiner Texte. So setzte der Schönberg-Schüler Egon Wellesz ein Prosagedicht aus Wie ich er sehe musikalisch um. Das Werk wurde 1910 in Budapest uraufgeführt, vgl. E. W.: Wie ein Bild: Skizze von Peter Altenberg. Budapest: Rozsavolgyi 1920. Und Alban Berg komponierte wenig später Fünf Lieder nach Ansichtskartentexten von Peter Altenberg (op. 4), deren Uraufführung am 31. März 1913 einen Tumult auslöste; vgl. Gert Mattenklott: wKeine Ansiedlungenw. Peter Altenbergs Texte der fünf Orchesterlieder Alban Bergs op. 4. In: Hofmannsthal-Blätter, Heft 27, 1983, S. 74-77, 79f., 82, 84, 86, 88-91, David P. Schroeder. Alban Berg and Peter Altenberg: Intimate Art and The Aestherics of Life. In: Joumal of the American Musicological Society 3 (1992), S. 261-293, sowie Wemer J. Schweiger: Das Skandalkonzert im Wiener Musikverein. In: Peter Altenberg Almanach. Lese-Heft des Löcker Verlags. Hrsg. von W.J. S. Wien: Löcker 1987, S. 34 f.

${ }^{112} \mathrm{Da}$ Altenberg seine Textensembles durchaus als Zyklen verstand, zeigt etwa der in Was der Tag mir zuträgt enthaltene Cyclus: Gedichte an Ljuba. 
von H.« sowie »Revolutionär« versammelt, und in Ashantee (1897) finden sich außer dem gleichnamigen Prosazyklus ${ }^{113}$ noch die Ensembles »Paulina« (11 Texte), „Une femme est un état de notre âme« (5 Texte) sowie »Hausball« ( 7 Texte). Ab der vierten Auflage von Wie ich es sebe (1904), in die auch die Texte des Bandes Ashantee Eingang fanden, wurden die bestehenden Ensembles dann mit dem Begriff "StudienReihe« versehen, was den engen Realitätsbezug der Prosastücke unterstreichen sollte. Seinen 1901 erschienenen Band Was der Tag mir zuträgt versah der Autor kurzerhand gleich mit dem Untertitel "fünfundfünfzig [ab der zweiten Auflage von 1902: "fünfundsechzig»] neue Studien«, wodurch er gleichsam das gesamte Buch zur "Studien-Reihe« machte. Der Vorgang der Assemblierung muß dabei als literarisches Strukturbildungsverfahren verstanden werden, das den über den - schon vom Umfang her sehr begrenzten - Einzeltext hinausgehenden ästhetischen Gestaltungsanspruch Altenbergs dokumentiert und nicht zuletzt darauf abzielt, die relative Formlosigkeit des Genres Prosagedicht wirkungsvoll zu transzendieren. Der lockere Zusammenschluß von eigenständigen Prosatexten tendiert natürlich zur Schaffung größerer narrativer Einheiten. So trägt denn auch das aus 11 Texten bestehende Ensemble Paulina in Was der Tag mir zuträgt die Bezeichnung "Novelle» im Untertitel. Die "Skizzenreihe Der Revolutionär wiederum mutet durch die den Inhalt vorwegnehmenden Überschriften der einzelnen Textabschnitte ( mille, »Der Revolutionär benimmt sich ungewöhnlich" oder »Man erfährt den Namen des Revolutionärs« etc.) wie ein auf mehrere kleine Kapitel verteilter Roman an.

Schon sehr bald allerdings gab Altenberg die zu großer Virtuosität entwickelte Technik der Reihenbildung ${ }^{114}$ wieder auf, begann damit, sein Ausdrucksspektrum auf alle Arten von Kurzprosa auszuweiten, und unternahm den Versuch, das Genre Prosagedicht immer stärker an die instrumentelle Rationalität moderner Lebenswirklichkeit anzukoppeln. Während Huysmans sein Textideal noch aus einem sprachmystischen Begründungszusammenhang heraus entwickelt hatte, präsentierte er die eigenen Kurzprosatexte nunmehr als Ergebnis eines sprachlichen Verfahren, das am Vorbild der Naturwissenschaft und den sich davon ableitenden Fabrikationstechnologien ausgerichtet war. Was er win gedrängtester Form zu Papier bringe» (Wz, S. 7), seien »Extracte،: "Das Leben der Seele und des zufäligen Tages, in 2-3 Seiten eingedampft, vom Überflüssigen befreit wie das Rind im Liebig-Tiegellı (Wz, S. 6) ${ }^{115}$

${ }^{113}$ In Briefen an den Verleger Samuel Fischer hat Altenberg die Textgruppe »Ashanteer explizit als "Skizzenreihe" bezeichnet; zitiert nach: Peter Altenberg. Leben und Werk in Texten und Bildern [1984]. Hrsg. von Hans Christian Kosler. Frankfurt a.M./Leipzig. Insel 1997 (= insel taschenbuch 5628), S. 130.

${ }^{114} \mathrm{Vgl}$. die Interpretationen altenbergscher $n S k i z z e n-R e i h e n$ bei Andrew Barker: "Die weiseste Ökonomie bei tiefster Fülle» - Peter Altenbergs Wie ich es sehe, S. 82-97, und Stefan Nienhaus: Das Prosagedicht im Wien der Jahrhundertwende. Altenberg - Hofmannsthal Polgar, S. 63-139.

${ }^{115}$ Bauer konstatiert in diesem Zusammenhang die Verwendung von Metaphern und Verglei- 
Hinter der angestrebten Ökonomisierung des Ausdrucks steht unverkennbar ein technokratisches Effizienzideal, das darauf gerichtet ist, nicht nur die Abläufe des Lebens, sondern auch die der Kunst nachhaltig zu rationalisieren - gemäß dem funktionalistischen Credo "Form hat dem Inhalt zu dienen! ${ }^{116}$ So ergibt sich eine regelrechte Stufenfolge reduzierten sprachlichen Ausdrucks: „Was sind denn meine Skizzen?! Extrakte von Novellen. Was sind denn meine Aphorismen?! Extrakte meiner Skizzen. Was ist denn, wenn ich gar nichts mebr schreibe?! Extrakte meines Heiligen Schweigens $\aleph^{117}$ Am Ende dieses Reduktionsprozesses wird literarische Gestaltung folgerichtig überflüssig, weil es nichts mehr zu gestalten gibt: "Ich werde immer kürzer in meinen Gedankengängen, und das heißt also immer besser, immer weniger Zeit raubend. Zum Schluß werde ich gar nichts mehr sagen. Das wird das beste sein. $\varkappa^{118}$

Doch auch wenn sich der österreichische Autor in bewußtem Gegensatz zu den Wortartisten seiner Zeit als "Dichter ohne Dichtungen" (Wz, S. 5f.) stilisierte oder gar von sich behauptete: 》Ich bin kein Dichter, kein Künstler.، (Wz, S. 3), hat er nie ernsthaft mit dem Gedanken gespielt, seine schriftstellerische Produktion tatsächlich zu beenden, wie das beispielsweise Arthur Rimbaud getan hat. Auch ist ihm - anders als seinem Kollegen Leopold von Andrian - die Erfahrung erspart geblieben, nicht mehr schreiben zu können und deshalb als Autor zu verstummen. Der Gedanke des wHeiligen Schweigensu ist denn auch, wie schon das sakralisierende Adjektiv andeutet, lediglich logischer Fluchtpunkt einer verzweifelten Anstrengung, welche die Literatur von allem Überflüssigen zu befreien und sie so mit dem Leben zu verschmelzen sucht. Die angestrebte Entschlackung der Kunst zielt freilich nicht wie bei den Vertretern des Ästhetizismus auf eine rreine, nur sich selbst genügende, autarke Sphäre des l'art pour l'art, sondern im Gegenteil auf eine möglichst vollständige Aufhebung in der Lebenswelt. Das Programm der Konzentration künstlerischen Ausdrucks konvergiert also paradoxerweise mit der Vorstellung der Entgrenzung des Ästhetischen. In Pròdroomŏs heißt es diesbezüglich prägnant: "Ästhetik ist Diätetik!

chen »propre à la chimie et non plus à l'alchimier; Roger Bauer: Le poème en prose autrichien: de Baudelaire à Peter Altenberg, S. 245. "Pour charactériser ses ipetites chosesı ou 'petits rienc [...], Altenberg renonce aux belles et savantes métaphores jadis empruntées à Huysmans - chez qui il était question de ssuc concretর, d'rosmazômes, d'huile essentieller et se rabat sur une autre, tirée du vocabulaire du jour." Ebd.

${ }^{116}$ Peter Altenberg. Fechsung, S. 263. In Bilderbögen der kleinen Lebens heißt es folgerichtig. "Das ganze ist eine Zeiterspamis. Es gibt heutzutage viele sonst tüchtige Menschen, die keine Zeit haben, 200 Seiten zu lesen. Diesen gibt man drei Seiten im Extrakte!، Peter Altenberg. Bilderbögen des kleinen Lebens. Berlin: Erich Reiss 1909, S. 164.

117 Peter Altenberg. Nachfechsung, S. 113. Schon in Pròdrŏmŏs heißt es: „Ein Aphorismus ist etwas, was dem Schreibenden einen Essay als Kommentar erspart, den Lesenden jedoch infolgedessen aufs höchste schockiert. « Peter Altenberg: Pròdrŏmǒs. Berlin: S. Fischer 1906, S. 129.

118 Peter Altenberg. Nachfechsung, S. 104. 
Schön ist, was gesund ist.. ${ }^{119}$ Die Aufgabe der Kunst wird kurzerhand auf den Aspekt der Lebenshilfe verkürzt. Dabei muß Altenbergs Bestreben, die Ästhetik auf das Wesentliche zu reduzieren, als Versuch gesehen werden, die aus dem Autonomisierungsprozeß des Sozialsystems Kunst resultierende Funktionslosigkeit der Literatur wieder rückgängig zu machen. ${ }^{120}$ Kunst soll demnach nicht mehr etwas im Grunde Überflüssiges, weil Produkt höchster sozialer Spezialisierung sein, sondern wieder einen festen Platz im Lebensvollzug erhalten. ${ }^{\mathbf{1 2}}$

Der Verzicht darauf, seine Texte "Dichtungenu zu nennen, entspringt denn auch keiner Bescheidenheitsrhetorik, sondern erweist sich vielmehr als Überbietungsgeste. Indem Altenberg seinen Hervorbringungen den Status des »Extractes« zuweist, überspringt er kurzerhand die Kluft von Zeichen und Bezeichnetem und postuliert einen Weg, um den alten Gegensatz zwischen dichterischem Wort und wirklichem Leben nicht so sehr zu schließen als zu umgehen. Er negiert den besonderen Status von Kunst in der modernen Gesellschaft und erklärt sie kurzerhand zu einem Teilaspekt der Alltagsrealität, die auf diese Weise das Prädikat »Dichtung 'Leben« ${ }^{122}$ zugeschrieben bekommt. ${ }^{123}$ Folgerichtig postuliert Altenberg, daß im Prinzip jeder,

119 Peter Altenberg. Pròdrŏmǒs, S. 128.

120 Altenbergs "Attacke auf den Systemstatus modemer Literatur" setzt die seit der Autonomwerdung ästhetischen Ausdrucks einsetzende lange Reihe von Projekten fort, die auf eine "durchgreifende Transformation [...] der funktionalen Systemdifferenzierung " abzielen, win deren Folge auch Kunst und Literatur ihren Status als rautonomer Gebilde verlieren sollenc Gerhard Plumpe: Epochen moderner Literatur. Ein systemtheoretischer Entwurf, S. 62. Künstlerische Entdifferenzierungsprogramme sind freilich beileibe kein exklusives Merkmal der klassischen Avantgardebewegungen nach 1910, wie Plumpe meint, sondern begleiten die Moderne von den Anfängen der Autonomieästhetik an.

121 Die Tatsache, daß Altenberg lebenslang keiner geregelten Berufstätigkeit nachging, sondem seinen Unterhalt durch großzügige monatliche Zahlungen seines Bruders und später durch finanzielle Zuwendungen seiner Freunde und Gönner bestritt, rückt allerdings nur allzu deutlich vor Augen, daß seine Existenz als Autor sich gerade dem Phänomen gesellschaftlicher Arbeitsteilung verdankt. Letztlich akzeptiert er die Organisationsform modemer Spezialisierung selbst, wenn er sich zu jenen Menschen mit geschärfter Wahmehmung zählt, deren Aufgabe es ist, wdie Vielzuvielbeschäftigten zum Verweilen zu bringen vor den Schönheiten der Weltu (Ws, S. 294).

122 Peter Altenberg. Die Auswahl aus meinen Büchern. Berlin: S. Fischer 1908, S. 6. Pym hat denn auch im Hinblick auf den für die Jahrhundertwende zentralen Begriff des Lebensı zu Recht bemerkt: whe term connected the aesthetic with the non-aesthetic spheres«; Anthony Pym: The Meaning of Lifer in European Aesthetics at the End of the Nineteenth century, with Implications for a Useful Definition of Modernism. In: The Turn of the Century / Le toumant du siècle. Modemism and Modernity in Literature and the Arts / Le modemisme et la modemité dans la littérature et les arts, S. 353.

123 Frühzeitig entdeckte Altenberg denn auch die Ansichtskarte als ihm gemäßes Schreibmedium, deren durch das kleine Format begrenzter Raum in Verbindung mit dem Realität verbürgenden Element der photographischen Abbildung in besonderer Weise seiner Ästhetik zu entsprechen schien. Vgl. Leonhard M. Fiedler: Peter Altenbergs Postkarten. In: Hof- 
auch der »Alltagmensch« (Ws, S. 293), ein Künstler sei: ${ }^{124}$ "Es ist ein Unrecht, dem Leben gegenüber, das wir alle führen, die Dichtungen nur den Herzen der Dichter zu überlassen, nachdem wir doch alle imstande sind, aus unserem einfachen Tagesleben Dichtungen zu schöpfen! ${ }^{125}$ Er leitet aus dieser Überzeugung den Appell ab: "Werdet reif zum Dichter in euch selber, daß ihr nicht aus zweiter Hand, auf literarischem Wege, die Schönheiten des Lebens empfangen müsset! ${ }^{126}$

Bezogen auf die eigene Textproduktion führt dies zu einer Aufwertung der Rolle des Rezipienten im Prozeß literarischer Kommunikation:

Altenberg fordert vom Leser die Bereitschaft ein, sich selbst am Schaffensakt zu beteiligen, denn eine Funktion seines extravaganten Gebrauchs des Schweigens, der durch die Satzzeichen - - - am Ende so vieler Sätze angedeutet wird, ist eben die Aufforderung, die Lükken zu füllen, damit jeder für sich das Werk des Dichters fertigstelle und damit letztlich selbst zum Dichter werde. ${ }^{127}$

Wie stark der österreichische Autor faktisch auf die Mitarbeit des Lesers bei der Bedeutungskonstitution setzte, verdeutlicht der Text Selbstbiograpbie.

Dem Leser bleibe es überlassen, diese Extracte aus eigenen Kräften wieder aufzulösen, in geniessbare Bouillon zu verwandeln, aufkochen zu lassen im eigenen Geiste, mit einem Worte sie dünnflüssig und verdaulich zu machen. Aber es giebt ıgeistige Mägen welche Extracte nicht vertragen können. Alles bleibt schwer und ätzend liegen. Sie bedürfen 90 Procent Brühe, Wässerigkeiten. (Wz, S. 6) ${ }^{128}$

mannsthal-Blätter, Heft 27, 1983, S. 72, 78, 81, 83, 85, 87, 91, Lco A. Lensing: Peter Altenberg's Fabricated Photographs. In: Vienna 1900: From Altenberg to Wittgenstein. Ed. by Edward Timms and Ritchie Robertson. Edinburgh: Edinburgh University Press 1990, S. 47-72, und das vierte Kapitel in Andrew Barker/Leo Lensing. Peter Altenberg: Rezept die Welt zu sehen, S. 133-167.

124 Er präsentiert sich damit als scharfer "Gegensatz zum Typus des poeta doctus«; Hans Christian Kosler: Vorbemerkung. In: Peter Altenberg. Leben und Werk in Texten und Bildern, S. 7. Entsprechend heißt es in Altenbergs letzter Buchveröffentlichung. "Ich wollte das Leben direkt, nicht auf gelehrten Umwegent! Peter Altenberg: Mein Lebensabend, S. 3. Und in einem Brief an Herwarth Walden aus dem Jahr 1909 ist zu lesen: "Ich bin ungebildet, das ist auch einer meiner Vorzüge. Z Zitiert nach: Peter Altenberg. Leben und Werk in Texten und Bildern, S. 154.

125 Peter Altenberg. Märchen des Lebens. Berlin: S. Fischer 1908, S. 213.

${ }^{126}$ Peter Altenberg. Die Auswahl aus meinen Büchem, S. 6.

127 Andrew Barker: Telegrammstil der Seele. Peter Altenberg - Eine Biographie, S. 85.

128 Altenberg nennt derartige Leser auch "Dyspeptiker der Seeles $\left(W_{z}, S .6\right)$ und spielt damit auf die "dyspepsie nerveuse von Huysmans' Romanheld des Esseintes an, dessen Gesundheit am Ende des Buches so zerrüttet ist, daß jede méchauffante essence de nourriture [...] une [...] irritation dans ses entrailles« hervornft; CEuvres complètes de ].-K. Huysmans, Bd. 7, S. 305. Daß sich die Wahl physiologischer Metaphern für psychische Prozesse sehr wahrscheinlich der Nietzsche-Lektüre Altenbergs verdankt, hat Simpson glaubhaft machen können; vgl. Josephine M.N. Simpson: Peter Altenberg. A Neglected Writer of the Viennese Jahrhundertwende. Frankfurt a.M./Bem/New York/Paris: Lang 1987 (= Europäische Hochschulschriften I/1001), S. 296-298. Schon Thomas Mann vertrat ja die Ansicht, daß 
Und in Auslegung, einem anderen Text des Bandes Was der Tag mir zuträgt, werden der Verfasser, der Vorleser und die Rezipientin eines Gedichts gleichermaßen als jene Faktoren benannt, welche die Wirkung des literarischen Kunstwerks hervorbringen: "Wir alle Drei zusammen sind der Dichter!! (Wz, S. 186) heißt es emphatisch.

Im Zuge der Umsetzung seines ästhetischen Programms verwischte Altenberg in seinen Texten immer deutlicher die Grenzen zwischen Fiktion und Nichtfiktion. Da ihm ja besonders an der Ungeschiedenheit von Leben und Kunst gelegen war, begann er schon in seiner zweiten Buchveröffentlichung Ashantee damit, extensiv auf den Darstellungsmodus des Autobiographischen zurückzugreifen. ${ }^{129}$ Die in Wie ich es sebe generierte Textrolle »P. A.« wurde zum tragenden Element dieses wie auch der späteren Bücher, was schließlich soweit ging, daß sich eine Publikation wie »Semmering 1912 "reichlich unverhüllt als eine Art tagebuchartiger Bericht über einen bestimmten Zeitabschnitt im Leben des Autors darbot. ${ }^{130}$ Vollends die zahlreichen Erinnerungen an Kindheitserlebnisse und Familienmitglieder verwandelten das Kürzel „P. A.«, das anfangs noch als Form des literarischen Maskenspiels gedeutet werden konnte, in ein Synonym des Schriftsteller-Ich, und so drängten die autobiographischen "Geschichten aus meinem Leben ${ }^{131}$ im Lauf der Werkentwicklung die Textsorte des fiktionalen Prosagedichts immer stärker zurück.

Um seine Anliegen zu beglaubigen, begleitete Altenberg die eigene Textproduktion von Anfang an durch biographische Performanz, ja die lebensweltliche Präsentation kann geradezu als habitueller und vestimentärer Ausdruck seiner Poetik angesehen werden. ${ }^{132}$ Sein Kleidungsstil entsprach dabei den Forderungen der Lebensre-

Altenberg »den literarischen Mut» für seine "Gesundheitslehre und Diätetik« maus gewissen Seiten des Ecce bomo schöpfter; Das Altenbergbuch. Hrsg. von Egon Friedell. Leipzig/Wien/ Zürich: Verlag der Wiener Graphischen Werkstätte 1921, S. 75.

Dem dient auch die Nutzung det Photographie, die Altenberg als einer der ersten Autoren (neben George) als wirkungsmächtiges Medium zur Selbststilisierung einsetzte. Schon die zweite Auflage von Wie ich es sehe enthält ja ein Bildnis des Schriftstellers auf dem Frontispiz. "Insgesamt sind acht der zwölf zu Lebzeiten Altenbergs veröffentlichten Bücher mit photographischen Porträts des Autors ausgestattet», des weiteren auch der postum erschienene Band Mein Lebensabend (1919); Andrew Barker/Leo Lensing. Peter Altenberg: Rezept die Welt zu sehen, S. 147. Siehe hierzu: Der photographierte Dichter. Hrsg. von Michael Davidis und Mathias Michaelis. Marbach a.N.: Deutsches Literaturarchiv 1989 (= Marbacher Magazin 51).

${ }^{130}$ Altenberg versuchte diesem unvermeidlich entstehenden Eindruck dadurch ein Stück weit entgegenzuwirken, daß er sich bei der Anordnung der einzelnen, häufig mit Datumsangaben versehenen Texte - „November 1912«, »9. März. Mein 53. Geburtstag«, "25. Jänner", Ostermontag auf dem Semmering etc. - bewußt nicht an die Chronologie hielt; Peter Altenberg. »Semmering 1912«, S. 44, 47, 53, 86.

131 Peter Altenberg. Märchen des Lebens, S. 100.

${ }^{132}$ Schon die Zeitgenossen registrierten, „daß er aus seiner Erscheinung ein Programm machteç zitiert nach: Peter Altenberg. Leben und Werk in Texten und Bildern, S. 130. Timms deutet Altenbergs Erscheinungsweise fälschlicherweise als Dandytum und führt sie auf psy- 
formbewegung um $1900,{ }^{133}$ wobei das Auftreten selbst betont unbürgerlich akzentuiert war. ${ }^{134}$ In Bann gezogen von seiner Selbstinszenierung verlagerte sich die öffentliche Wahmehmung nach und nach vom Werk auf die Person. ${ }^{135}$ Dies ging schließlich soweit, daß Altenberg in Reiseführern der Jahrhundertwende als eine der

chologische Konflikte zurück; vgl. Edward Timms: Peter Altenberg - Authenticity or Pose. In: Fin de Siècle Vienna. Proceedings of the 2. Irish Symposium in Austrian Studies held at Trinity College, Dublin, 28 Febr. - 2 March 1985. Ed. by Gilbert Carr and Eda Sagarra. Dublin: Trinity College 1985, S. 126-142.

133 So berichtet etwa Polgar: "Im karierten Anzug mit zu kurzen Hosen, den Ledergürtel sportlich umgeschnallt, ohne Hut, sandalenklappemd, die Zwickerschnur breit wie ein Meßband, den keulenförmigen, knolligen Stecken unterm Arm, stocherte er [...] über den Graben.» Alfred Polgar: Wirkung der Persönlichkeit. In: Das Altenbergbuch. Hrsg. von Egon Friedell, S. 272. Und Auemheimer erinnert sich: „Er ging nacktfüßig, auf Sandalen einher, im Winter in einem flatternden Havelock, im Sommer in einer Art Radfahrerdreß, mit sportmäßig geknüpfter Krawatte. Die Kappe war tief in die Stim gedrückt, der grimmige Schnauzbarrt hing wüst herunter, von einem fingerbreiten Zwickerband malerisch umflattert, und in der Hand hielt er einen dicken, keulenartigen Spazierstock, den er in der Mitte umklammerte und im Gehen rabiat hin und herschwang." Zitiert nach: Peter Altenberg. Leben und Werk in Texten und Bildem, S. 130. Bei allen Anwandlungen von Asketismus jedoch war Altenberg durchaus kein Muster an Bedürfnislosigkeit, keine mreincarnation of the spirit and person of Diogenes«, auch wenn er sich selbst als »modemen Diogenes« bezeichnete; Randolph J. Klawiter: Peter Altenberg and das junge Wien, S. 27, und Peter Altenberg- "Semmering 1912 , S. 129. Daß dies im wesentlichen eine falsche Vorstellung war, die Altenbergs Umwelt - von dessen Selbststilisierung animiert - auf den Autor projizierte, illustriert sehr schön eine Anekdote, die Hofmannsthal in seinen Aufzeichnungen notiert: "Anfang 1904 ging es Altenberg psychisch und pekuniär sehr schlecht. Es wurde in einem Haus des Kreises eine Versammlung der Freunde einberufen, um zu beraten, wie ihm zu helfen wäre. Altenberg selbst, in einem Fauteuil, etwas abseits der anderen, aber im gleichen Zimmer, wohnt der Beratung bei. [...] IIch bin ein Bettler und ein Sterbender, murmelt er vor sich hin, swas wollt ihr von mir? Laßt mich ruhig sterben.، [...] Da steht die hübscheste Frau des Kreises auf: [...] IIch liebe Altenberg mehr als ihr aller, sagt sie, rich liebe seine Seele und die Gebärden seiner Seele. Und ich weiß nichts Schöneres, als ihn so sterben zu sehen, in einem Winkel, mit einer dürftigen Decke zugedeckt. $O$ rührt nicht an das Wunder dieses Sterbens. Pauvre Lélian! wer wollte ihn um die Schönheit seines Endes bringen? - Da schnellt Altenberg wütend aus seinem Fauteuil auf: 'Dumme Gans, schreit er sie an, verfluchte dumme Gans! ich will nicht sterben! ich will leben! ich will ein warmes Zimmer mit einem Gasofen, einen amerikanischen Schaukelstuhl, eine Rente, Orange Jam, Kraftsuppe, Filets mignon; ich will lebenk «(H-GW X, S. 456) Altenbergs hochentwickelte Diätetik ist denn auch nur vor dem Hintergrund einer weit fortgeschrittenen Industrialisierung, etwa der Nahrungsmittelproduktion und -verarbeitung, zu denken. Hofmannsthal hat dies in seiner Besprechung von Wie ich es sebe bereits genau erkannt, charakterisiert er dort doch Altenbergs Verfahren als wdie Anbetung des höchst Künstlichen, das sich dem höchst Natürlichen annähert" (H-GW VIII, S. 227).

${ }^{134}$ Bauer konstatiert bei Altenberg wun dandysme inversé de snob aux allures de clochardk; Roger Bauer: Le poème en prose autrichien: de Baudelaire à Peter Altenberg, S. 239.

${ }^{135}$ Dazu trug natürlich auch der Umstand bei, daß Altenberg jahrelang für Kürschners Literaturkalender das Café Central als offizielle Adresse angab; vgl. hierzu Wolfgang Bunzel: 
Hauptattraktionen Wiens firmierte. Für die Zeitgenossen war der Autor denn auch, wie Soergel treffend konstatiert, wzunächst ein Lebenskuriosum, dann erst ein Dichter ${ }^{136}$. Altenberg selbst kam eine solche Verschiebung des Interesses durchaus entgegen, ging es ihm doch darum, Leben und Schreiben als ungeschiedene Einheit vorzuführen. Seine Texte begriff er konsequenterweise immer weniger als fiktionale Gegenentwürfe zur Realität im Kunstraum der Literatur, sondern wollte sie zunehmend als lebenspraktische Handreichungen nahe der Alltagskommunikation verstanden wissen, denn: mKunst ist etwas, was überwunden werden muß durch $\mathrm{Na}$ türlichkeit, durch Zweckemäßigkeitk ${ }^{137}$

Und so rückte der Autor spätestens ab 1906 fast vollständig von fiktionalen Darstellungsformen ab. ${ }^{138}$ Er begründete dies damit, daß die "Wichtigkeit", die in den Texten "verborgen liegt, [...] die skünstlerische Spielereik der Ausgestaltung " verbiete - ein Argument, das direkt auf das selbstreferentiell-omamentale Kunstverständnis des Ästhetizismus zielt:

Zum Künstlertum gehört eine gewisse kühle, den Menschen ferne Herzlosigkeit. Dort aber, wo man helfen, lindern, heilen möchte, wird man sgestrenger Arztı und Philosoph. [...] Das Wort künstlerisch, stammt aus bleichen fahlen schlimmen Herzen, denen der unglückselige Nebenmensch gleichgültig, ja verhaßt und verächtlich ist! Die Kunst aber kann nur eines jener vielen Mittel sein, die darbende, in Verlogenheiten versunkene Menschheit zu erretten, zu erlösen von ihren zahlreichen Erkrankungen, Verirrungen! ${ }^{139}$

Altenberg ging schließlich soweit, jede Art von künstlerischer Gestaltgebung zu verurteilen. So heißt es etwa in dem Band Fechsung (der Titel ist sein altertümlicher österreichischer Ausdruck für Ernte ${ }^{149}$ : „Form, du größter frechster Hochstapler von leeren Gehirnen, leeren Herzen! Ich hasse dich! Ich verachte dich! « ${ }^{141}$

Kaffeehaus und Literatur in Wien um 1900. Stärker als jeder andere Autor seiner Zeit führte Altenberg also ein im direkten Wortsinn öffentliches Leben.

136 Albert Soergel: Dichtung und Dichter der Zeit. Eine Schilderung der deutschen Literatur der letzten Jahrzehnte, S. 481. Nach Friedell wurde wsein Name zu einem Generalnenner für modeme Paranoia, Sensationslust, Selbstberäucherung und Originalitätshaschereiç, Das Altenbergbuch. Hrsg. von Egon Friedell, S. 10.

137 Peter Altenberg. Der Nachlaß, S. 15.

${ }^{138}$ Die weitgehende Abkehr von fiktionalen Textsorten als Ausdruck wvon Altenbergs wachsendem linguistischen Skeptizismus zu deuten - wie Barker dies tut -, rückt den Autor fälschlicherweise in die Nähe moderner Sprachkritik (Nietzsche, Hofmannsthal, Mauthner) und übersieht, daß insbesondere seine späteren Werke durch ein fast schon naiv anmutendes Vertrauen in die Sprache gekennzeichnet sind; Andrew Barker: Telegrammstil der Seele. Peter Altenberg - Eine Biographic, S. 71.

139 Peter Altenberg. Pròdrǒmǒs, S. 95. Die exzeptionelle Bedeutung dieses nicht zufällig Bekenntnis überschriebenen programmatischen Textes zeigt sich daran, daß er in vier weitere Buchpublikationen Altenbergs (Bilderbögen des kleinen Lebens, Nexes Altes, Nacbfechsung, Mein Lebensabend) übernommen wurde.

140 Andrew Barker: Telegrammstil der Seele. Peter Altenberg - Eine Biographie, S. 278.

${ }^{141}$ Peter Altenberg. Fechsung, S. 264. Friedell pries Altenberg denn auch - dessen Selbstdeu- 
Obwohl die ästhetischen Grundüberzeugungen des österreichischen Autors im Laufe seines Schaffens im wesentlichen gleichblieben, veränderte sich doch der Charakter seiner Texte vom Früh- zum Spätwerk ganz erheblich, ja gewisse Parameter der literarischen Produktion verkehrten sich geradezu - gewissermaßen unter der Hand - in ihr Gegenteil. So höhlte Altenberg seinen an den Naturalismus gemahnenden mimetischen Schreibgestus durch die immer stärkere Fokussierung der Darstellung auf das wahrnehmende Subjekt innerlich aus. Damit aber verschob sich der Akzent entgegen allen auktorialen Beteuerungen vom "Wie ich es seber zum "wie itb es sehe ${ }^{142}$. Ähnlich konterkarierte der Autor das vor allem in Was der Tag mir zuträgt propagierte und für seine ersten Buchveröffentlichungen auch strukturell konstitutive Ökonomieideal in den nach Prödrömǒs erschienenen Bänden, indem er nicht nur einzelne Texte z.T. wörtlich, z.T. geringfügig variiert ${ }^{143}$ - manche sogar ergänzt und erweitert $^{144}$ - wieder abdruckte, sondem seine gesamte sprachliche Rhetorik unter das Gesetz insistierend-repetitiver Nennung stellte. Von einem nabgekürqten Verfabren«, bei dem alles „Überflüssige« weggelassen oder "weise verschwiegen« wird, kann ernsthaft nicht mehr die Rede sein. Schließlich schränkte Altenberg auch den Deutungsspielraum seiner Texte radikal ein. Auf typographischer Ebene schlägt sich dieser pädagogische Versuch der Leserlenkung im häufigen Sperrdruck von Worten nieder. Wenn Textaussagen aber "für $\gg$ Minderbemittelte im Geister spationirk ${ }^{145}$ werden, dann ist der Rezipient zum Empfänger auktorialer Weisungen degradiert.

Altenbergs literarische Produktion bewegt sich, wenn auch nicht zielgerichtet linear, so doch der Tendenz nach »vom künstlerischen Prosagedicht zum reinen Ratgebertext ${ }^{146}$. In den späteren Werken finden sich neben dezidiert biographisch ausgerichteten Genres wie Brief und Tagebuch wu.a. Lehrgespräche, Dialogszenen, medizinische Referate, philosophische Reflexionen, Buchbesprechungen und eine Rei-

tung folgend - als Dilettanten und unterstrich die »Formlosigkeitu seiner Texte; Danach sei "[...] Formlosigkeit die neue und spezifische Grundform Peter Altenbergs. Sie ist sein morphologischer Grundriß, sein Diagramm. Seine Dichtungen sind amorph oder vielleicht, genauer gesagt, kristallinisch: keine Form haben ist eben auch eine Art Form.1; Egon Friedell: Ecce Poeta, S. 151. Simpson dagegen deutet die Heterogenität von Altenbergs späten Texten kurioserweise als wthe product of a restless search for form«; Josephine M.N. Simpson: Peter Altenberg. A Neglected Writer of the Viennese Jahrhundertwende, S. 352.

${ }^{142}$ Peter Altenberg. Pròdrómǒs, S. 155. Die "Betonung auf dem Verb war nach Ansicht Altenbergs »die einzig richtiger; ebd.

${ }^{143}$ Beispiele dafür nennt Irene Köwer: Peter Altenberg als Autor der literarischen Kleinform. Untersuchungen zu seinem Werk unter gattungstypologischem Aspekt, S. 313, Anm. 228.

144 Barker und Lensing konnten nachweisen, daß Altenberg in Zeitungen erschienene Texte ausgeschnitten und für die spätere Buchausgabe dann handschriftlich ergänzte, was deren Umfang zuweilen beträchtlich »verlängert» hat, Andrew Barker/Leo Lensing. Peter Altenberg. Rezept die Welt zu sehen, S. 55.

145 Peter Altenberg an Karl Kraus, 7.12.1911; ebd., S. 248.

146 Stefan Nienhaus: Das Prosagedicht im Wien der Jahrhundertwende. Altenberg - Hofmannsthal - Polgar, S. 205. 
he anderer, noch schwerer zu bestimmender Gattungen ${ }^{147}$, die jedoch allesamt in einem - zugegeben weitgefaßten - Rahmen kurzer Prosa verbleiben. Der Autor trug damit der Vielfalt lebensweltlicher Textsorten (und gleichsam präliterarischer reinfacher Formen، wie Märchen, Parabel oder Legende ${ }^{148}$ ) Rechnung, bändigte aber ihre anarchische Vielfalt, indem er in seinen Buchveröffentlichungen einerseits den Umfang der Texte rigide auf das Höchstmaß von etwa drei Druckseiten limitierte und andererseits den slebensnahen, weil auf den Kontext der Alltagskommunikation verweisenden Gestaltungsmodus der Prosa zur Ausdrucksnorm erhob. Durch diese ebenso unauffällige wie wirkungsvolle Filterung entstand ein relativ homogener Typus von Kurzprosa auf der Grenze von Fiktion und Nichtfiktion, der charakteristisch für die mittlere und späte Phase seines Schaffens ist. Und da Altenberg den häufig als Synonym für Prosagedicht gebrauchten Terminus skizzer zur Bezeichnung seiner Texte beibehielt, wurden auch seine späteren Hervorbringungen gemeinhin als poèmes en prose oder doch zumindest prosagedichtähnliche Gebilde rezipiert. Das zu Beginn seiner Autorschaft etablierte Gattungslabel blieb also eine Art unifizierender Sammelbegriff für die gesamte literarische Produktion dieses Schriftstellers, auch wenn in dessen Euvre schon längst andere Formen der Kurzprosa und nonfiktionalen Narrativik dominierten und er de facto zum Arrangeur disparatester textueller Kleinformen geworden war. ${ }^{149}$

\section{Exkurs: Prosagedicht und Feuilleton - Versuch einer Abgrenzung}

Auf Grund der Tatsache, daß bei Altenberg zahlreiche Textsorten begegnen, die auf den medialen Kontext der Zeitung verweisen (Buchrezension, "Varietée-Kritik«, "Essay“, Ausstellungsbesprechung oder Theaterbericht ${ }^{150}$, wurde sein Werk gern in die Nähe journalistischer Gestaltungsformen gerückt. Thomas Mann war einer der ersten, der im Hinblick auf dessen Texte von »lyrischem Journalismus « ${ }^{151}$ sprach. Nadler schloß sich dieser Einschätzung an - wseine hinaufgelobte kleine Prosa ist nicht mehr als lyrische Lokalspalte« -, funktionierte sie aber zur antisemitisch motivierten ästhetischen Abrechnung um; danach habe Altenberg lediglich den njüdi-

${ }^{147}$ Burkhard Spinnen: Idyllen in der Warenwelt. Peter Altenbergs Pròdrömŏs und die Sprache der Werbung, S. 135. Siehe hierzu auch das »Titelregister " bei Andrew Barker/Leo Lensing: Peter Altenberg: Rezept die Welt zu sehen, S. 349-388.

148 Vgl. den Band Märchen des Lebens, die Texte Märchen (S. 120f.) und Parabel (121f.) in Pròdrömós sowie das Kurzprosastück Legende (S. 36) in Vila ipsa.

149 So heißt es etwa in Fechsung explizit: "Meine Bücher sind ein Sammelsurium von allem Möglichen, Wichtigem«; Peter Altenberg: Fechsung, S. 263. Altenberg wollte diesen Band, wie er in der Folgepublikation schreibt, ursprünglich gar "Sammelsurium 1914« nennen; Peter Altenberg. Nachfechsung, S. 182.

${ }^{150}$ Siehe Peter Altenberg. Pròdrōmors, S. 155; Märchen des Lebens, S. 208; Was der Tag mir zuträgt. Fünfundfünfzig neue Studien, S. 234-247.

151 Das Altenbergbuch. Hrsg. von Egon Friedell, S. 74. 
schen Zeitungsstil verfeinert ${ }^{152}$. Spätere Forscher bewerteten den konstatierten Zusammenhang zwischen Literatur und Presse neutraler. Schäfer etwa stellt fest, daß die »Themen« des Autors »häufig mit den skleinen Meldungen der Tageszeitungen« korrespondieren, und schließt daraus: "Altenbergs Kurzprosa steht in der Tradition des Wiener Feuilletons ${ }^{153}$. Köwer deutet die Genrevielfalt in dessen CEuvre als "Versuch, sich dem Rezipienten innerhalb der feuilletonistischen Gattungsform in umfassender Weise zuzuwenden ${ }^{154}$. In ähnlicher Weise sieht Nienhaus Altenbergs Texte sich wvon der relativen Autonomie des künstlerischen Prosagedichts [...] zum sWiener Feuilleton « bewegen, jener „Form kurzer Prosa, wie sie sich in den Literatur-Spalten der Wiener Zeitungswelt fest etabliert» habe und bei der es in erster Linie auf die »Unterhaltungsfunktion “ ${ }^{155}$ ankomme. Barker schließlich benennt - einen Hinweis Nadlers aufgreifend - konkret Daniel Spitzers Wiener Spaziengänge, ndie jahrelang einen integralen Teil der Neuen Freien Presse gebildet hatten«, als "Vorläufer ${ }^{156}$ von Altenbergs journalistisch wirkender Darstellungstechnik. Freilich wäre es vorschnell, von vagen Analogien ausgehend gleich einen unmittelbaren Zusammenhang zwischen einem nicht näher spezifizierten Feuilletonstil ${ }^{157}$ und dem Schreibpro-

152 Josef Nadler: Literaturgeschichte der deutschen Stämme und Landschaften. Bd. 4: Der deutsche Staat (1814-1914). Regensburg. Habbel 1928, S. 914.

153

Hans Dieter Schäfer: Peter Altenberg und die Wiener "Belle Epoque», S. 81. Zu diesem Traditionszusammenhang siehe Hubert Lengauer: Das Wiener Feuilleton im letzten Viertel des 19. Jahrhunderts. In: Lenau-Fonm 9/10 (1977/78), S. 60-77.

154 Irene Köwer: Peter Altenberg als Autor der literarischen Kleinform. Untersuchungen zu seinem Werk unter gattungstypologischem Aspekt, S. 192.

155 Stefan Nienhaus: Das Prosagedicht im Wien der Jahrhundertwende. Altenberg - Hofmannsthal - Polgar, S. 203.

156 Andrew Barker: Telegrammstil der Seele. Peter Altenberg - Eine Biographie, S. 79. Zum publizistischen Profil des Veröffentlichungskontextes vgl. Doris Chamrath: Das Feuilleton der Neuen Freien Presse. Diss. (Masch.) Wien 1959.

${ }^{157}$ Die Ansicht, daß der Begriff ,Feuilletons nicht ein bloßer Kollektivsingular für verschiedenartige Textsorten im Veröffentlichungskontext des Mediums Zeitung darstellt, sondem als eigenständige Gattung anzusehen sei, geht auf Haacke zurück; vgl. Wilmont Haacke: Feuilletonkunde. Das Feuilleton als literarische und joumalistische Gattung. 2 Bde. Leipzig. Hiersemann 1942, sowie W. H.: Handbuch des Feuilletons. 2 Bde. Emsdetten: Lechte 1952. Aufgegriffen und weiterentwickelt hat diese These dann vor allem Knobloch, der auch eine Verbindung zwischen Prosagedicht und Feuilleton behauptet; vgl. Heinz Knobloch: Vom Wesen des Feuilletons, mit Studienmaterial Theorie und Praxis des Feuilletons. Halle: VEB Verlag Sprache und Literatur 1962 (= Beiträge zur Gegenwartsliteratur 23). Dagegen hat etwa Preisendanz geltend gemacht, daß wdas Attribut feuilletonistisch [...] von der Unterschiedlichkeit und Heterogenität der damit versehenen Texte zu sehr abstrahiert从; Wolfgang Preisendanz: Der Funktionsübergang von Dichtung und Publizistik bei Heine, S. 348, Anm. 11. Eine historisch wie theoretisch anspruchsvolle Grundlage zum Verständnis des Phänomens Feuilleton hat in jüngerer Zeit Oesterle geliefert, siehe hierzu Günter Oesterle: "Unter dem Strich«. Skizze einer Kulturpoetik des Feuilletons im neunzehnten Jahrhundert. In: Das schwierige neunzehnte Jahrhundert. Germanistische Tagung zum 65. 
gramm des Autors konstatieren zu wollen, wie dies etwa Simpson tut, wenn sie behauptet: win choosing to write in a succinct feuilletonistic manner, Altenberg was clearly responding to consumer demand ${ }^{158}$. Immerhin weist dieser selbst darauf hin, daß seine Texte »keine Tragkeraft für Feuilletons etc." besäßen: sIch habe nur sBlitzlichtwirkungs, während eine Zeitung ${ }^{\text {Raum-füllends wirken muß. }}{ }^{159}$ Es gilt daher, das Verhältnis des österreichischen Autors zum auf Aktualität fixierten Medium Zeitung zu bestimmen, um so mögliche Einflüsse journalistischer Textformen auf dessen literarische Produktion aufzuspüren. ${ }^{160}$ Dies erscheint auch deshalb ratsam, weil die Gattung des Prosagedichts von verschiedenen Seiten immer wieder mit der feuilletonistischen Schreibart in Verbindung gebracht worden ist. ${ }^{161}$

In Altenbergs Texten selbst jedenfalls wird der mediale Kontext der Tagespresse mehrfach thematisiert, was nicht verwundern kann angesichts ihres Vermögens, zumeist nichtfiktionale, in alltagsnahen Zweckrelationen stehende Kurzprosa massenhaft $z$ verbreiten. Allerdings liefert die Distributionsform Zeitung im allgemeinen eben nicht "das Leben selbst«, das Altenberg so verzweifelt beschwört, sondern entstellt die vorgefundene Wirklichkeit in ähnlicher Weise wie die Institution Kunst. Diese medial bedingte Zurichtung aber lenkt entweder von den Epiphanien des Alltags ab oder deformiert sie zu bloßen Lektüreanreizen, die auf nichts anderes als auf kommerzielle Verwertungsinteressen abzielen. Besonders deutlich zeigt sich das in zwei Texten, welche die Tätigkeit des Zeitungsschreibers in den Mittelpunkt rücken: Reporter und Dicbter sowie Vita ipsa. Das Leben selbst! Während im ersten Fall der jour-

Geburtstag von Eda Sagarra im August 1998. Hrsg. von Jürgen Barkhoff, Gilbert Carr und Roger Paulin. Mit einem Vorwort von Wolfgang Frühwald. Tübingen: Niemeyer 2000 (= Studien und Texte zur Sozialgeschichte der Literatur 77), S. 229-250.

158 Josephine M.N. Simpson: Peter Altenberg. A Neglected Writer of the Viennese Jahrhundertwende, S. 290. Einen engen Konnex zwischen dem Zeitungsfeuilleton und den literarischen Formen der Jahrhundertwende hat vor allem von Kotze hergestell, vgl. Hildegard von Kotze: Feuilleton und Feuilletonismus als Stilmerkmal impressionistischer Kulturepochen. Diss. Berlin 1957.

159 Zitiert nach: Irene Köwer. Peter Altenberg als Autor der literarischen Kleinform. Untersuchungen zu seinem Werk unter gattungstypologischem Aspekt, S. 315, Anm. 276.

${ }^{160}$ Freilich kann es hier nicht darum gehen, sdie Beeinträchtigungen, die Altenbergs Produktion durch den Veröffentlichungsmodus der Presse erlitt', zu beklagen, wie Spinnen das tut; Burkhard Spinnen: Idyllen in der Warenwelt. Peter Altenbergs Prödrömŏs und die Sprache der Werbung, S. 134.

161 So sieht Knobloch das Feuilleton als mein Produkt der Wechselwirkung von Literatur und Joumalistik«, wobei von seiten der Literatur besonders die Gattung des Prosagedichts anregend gewirkt habe: „Äußerlich deutlich voneinander unterschieden, ergeben sich zwei Entwicklungslinien, die inhaltlich zusammenhängen. Das Genre Feuilleton kommt aus der französischen Literatur [nämlich der Tradition des poème en prose] und aus der deutschen Journalistik [wie sie sich etwa in Bömes Briefen uus Paris verkörpert]. Heinz Knobloch: Vom Wesen des Feuilletons, S. 110. Ein Text wie Baudelaires Prosagedicht Un plaisant ist denn auch für Knobloch weinwandfrei ein Feuilleton im Sinne des Genresж; ebd., S. 101. 
nalistische Bericht an der Oberfläche der Dinge bleibt und nur die konkurrierende Darstellung des »Dichters" (vgl. Ws, S. 248-251) einen Einblick in die komplexe Innenwelt der beschriebenen Figuren gibt, zerstört im zweiten die subjektiv-psychologisierende Ausschmückung einer lakonischen »Gerichtssaalnotiz« durch einen »Jour-

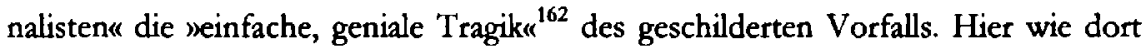
wird das eigentliche Vertextungsziel verfehlt, weil die auf die Bedürfnisse des Mediums Zeitung zugeschnittene Textform dem Lebenssubstrat nicht gerecht zu werden vermag. Einmal reduziert sie die vielfältigen Facetten der Wirklichkeit auf bloße Faktizität, das andere Mal unterwirft sie die sprosaische` Realität den Genrekonventionen des Feuilletons.

Köwer hat denn auch zu Recht auf Altenbergs Ambivalenz gegenüber der Presse hingewiesen. ${ }^{163}$ Immer dann, wenn sich der Autor aus freien Stücken journalistischen Verbreitungsformen intensiver zuwendet, tendieren seine Beiträge dazu, die medialen Spezifika des jeweiligen Blattes zu unterlaufen. ${ }^{164}$ Als er von November 1898 bis Juli 1899 als Theaterkritiker für die Wiener Extrapost schrieb, munterschieden sich" seine Texte wmerklich von herkömmlichen Theaterbesprechungen ${ }^{165}$. Und in der Halbmonatsschrift Kunst, die er von Herbst 1903 bis Frühjahr 1904 leitete und redigierte, ging er gar so weit, die Existenzberechtigung der Institution Kunst insgesamt infrage zu stellen. Doch auch in der Zeit nach dem Bankrott des väterlichen Geschäftes (1905), als er aus materiellen Gründen dazu gezwungen war, seine Texte in Tages- und Wochenperiodika zu verwerten, hat sich Altenberg weder zu einem universell einsetzbaren Zeitungsschreiber noch zum Feuilletonisten im engeren Sinn entwickelt. Schon der Extrapost waren wseine Beiträge zu wenig pressekonform ${ }^{166}$. Bei näherem Hinsehen bestehen denn auch wenig Gemeinsamkeiten zwischen Altenbergs Kurzprosa und den Feuilletons eines Ferdinand Kürnberger bzw. Friedrich Schlögl ${ }^{167}$ oder den Wiener Spaziengängen Daniel Spitzers. Barker und

162 Peter Altenberg. Märchen des Lebens, S. $75 f$.

163 "Einerseits ist er journalistisch tätig [...], andererseits hat er vom Zeitungswesen Abstand genommen.« Irene Köwer: Peter Altenberg als Autor der literarischen Kleinform. Untersuchungen zu seinem Werk unter gattungstypologischem Aspekt, S. 149.

164 Es kann deshalb keine Rede davon sein, daß Altenberg "sich und die Intentionen seiner Prosa im Umfeld der Presser mzerstreute habe; Burkhard Spinnen: Idyllen in der Warenwelt. Peter Altenbergs Pròdrömŏs und die Sprache der Werbung, S. 135.

165 Andrew Barker: Telegrammstil der Seele. Peter Altenberg - Eine Biographie, S. 126. Vgl. hierzu Robert Werba: Ein Außenseiter der Theaterkritik. Peter Altenberg und das Wiener Theaterjahr 1898/1899.

${ }^{166}$ Burkhard Spinnen: Idyllen in der Warenwelt. Peter Altenbergs Pròdrömŏs und die Sprache der Werbung, S. 134. In Essay. Versuch dokumentiert Altenberg seine Zeitungstexte gemeinsam mit den ablehnenden Reaktionen der Redaktion und führt so nachgerade lustvoll seine Unfähigkeit vor, den Strukturmerkmalen journalistischer Genres (wie Ausstellungsbericht, Essay, Rezension, Theaterkritik) entsprechen zu können; vgl. Wz, S. 234-247.

${ }^{167} \mathrm{Zu}$ den Feuilletontexten dieser beiden Autoren vgl. L. [eigh] H. Bailey: Ferdinand Kümber- 
Lensing haben mit Recht darauf hingewiesen, daß das auf $A$ rebours verweisende Mottozitat von Wie ich es sebe nicht zuletzt die Funktion der Abgrenzung hat:

Indem Altenberg Huysmans zzitiertr, versucht er auch die ästhetischen Reaktionen seiner Leser von der begrenzten österreichischen Bezugssphäre abzulenken, die seine Stücke nahelegen könnten, und hin zu einer breiteren europäischen Tradition zu führen. Er war der Meinung, daß seine Werke eine ganz andere Einstellung des Lesers verlangten als die Skizzen Spizzers. ${ }^{168}$

Die einzelnen, heterogenen Textsorten, die unter dem Begriff ‘Feuilleton zusammengefaßt werden, müssen - im Vergleich zum Prosagedicht - eher als zwar benachbarte, im wesentlichen aber konkurrierende Ausdrucksformen betrachtet werden, deren Genrestruktur entscheidend von ihrem medialen Verwertungskontext bestimmt ist.

Das eigentliche Wirkungsfeld von Altenbergs Kurzprosa, um das sich der Autor trotz seines sich rapide verschlechternden Gesundheitszustandes intensiv und mit großer Sorgfalt kümmerte, blieb die traditionelle, der Sphäre der sschönen Literatur zugeordnete Publikationsform Buch. ${ }^{169} \mathrm{Da}$ als Schriftsteller für ihn mur pure, faktische Informationen« zählen, sdistanziert« er »sich von der kommentierten Realität, die die Zeitung übermittelt ${ }^{170}$. Um so mehr schätzt er dagegen die Lakonie einer sunaufbereitetenc Nachricht ${ }^{171}$ oder auch die visuelle Veranschaulichung einer Abbildung, ${ }^{172}$ die auf Grund ihres Status als Information im >Rohzustand jederzeit zum Stimulus für den »Dichter« werden kann - gemäß dem Grundsatz: "[...] jedes Lokalereignis einer Tageszeitung kann Dir die Tiefen des Lebens eröffnen, alles Tragische und Lächerliche, wie die Tragödien Shakespeares! ${ }^{173}$ Die periodische Presse fun-

ger, Friedrich Schlögl and the Feuilleton in Gründerzeit Vienna. In: Austrian Life and Literature 1780-1938. Eight Essays. Ed. by Peter Branscombe. Edinburgh: Scottish Academic Press 1978, S. 59-71.

168 Andrew Barker: Telegrammstil der Seele. Peter Altenberg - Eine Biographie, S. 90.

169 Der Umstand, daß auch einige der namhaften Feuilletonautoren ihre Beiträge später gesammelt in Buchveröffentlichungen vorgelegt haben - so publizierte Schlögl etwa die Bände Wiener Blut (1873), Wiener Lust (1875) und Wienerisches (1882), und Spitzers Wiener Spaziergänge (1869-86) füllten gar sieben Bücher -, suggerierte fälschlicherweise weitergehende $\mathrm{Pa}$ rallelen zwischen ihnen und Altenberg. Irene Köwer: Peter Altenberg als Autor der literarischen Kleinform. Untersuchungen zu seinem Werk unter gattungstypologischem Aspekt, S. 150.

171 So druckt Altenberg etwa den Wortlaut eines »Privattelegramms» oder auch eines Testaments ab; vgl. Peter Altenberg. Fechsung, S. 147 und 229.

172 In Fechswng läßt ex beispielsweise eine Todesanzeige faksimilieren; vgl. ebd., S. 172.

${ }^{173}$ Peter Altenberg. Märchen des Lebens, S. 213. Den deutlichsten Beleg für diese Anregerfunktion stellt wohl das Prosastück Locale Chronik (vgl. Wz, S. 159-165) dar, das auf einer Zeitungsnotiz im Illustrirten Extrablatt basiert. Die Nachricht selbst samt begleitender Illustration ist abgedruckt bei Andrew Barker/Leo Lensing: Peter Altenberg: Rezept die Welt zu sehen, S. 134. Altenberg stilisierte Locale Chronik im Rückblick zur Urszene seiner literarischen Karriere; vgl. Peter Altenberg. "Semmering 1912«, S. 35f. 
giert also in erster Linie als eine Art schriftlich-visueller Realitätsspeicher und erweist sich solange als nützlich und wertvoll, als die Integrität der mitgeteilten Lebenszeugnisse gewahrt bleibt und diese nicht in vorgegebene Darstellungsmuster gepreßt werden. Auf Grund ihrer weiten Verbreitung in fast allen sozialen Schichten kann sie zudem - im Unterschied zum Buch - als ein demokratisches Medium gelten, das seinen Lesern unterschiedslos Zugang zu den lebensweltlichen Informationsressourcen gewährt. Insofern eignet sich die Zeitung prinzipiell zwar in besonderer Weise, um dem in den Reproduktionsprozeß eingebundenen Durchschnittsmenschen wdie Romantik, die Poesie des Tages und der Stunde näher[zu]rücken ${ }^{174}$, allerdings werde diese einzigartige Fähigkeit nicht genügend genutzt: »Alle Tageszeitungen sind angefüllt mit Tragik, Romantik, Humor, Poesie. Aber niemand nimmt sich die Mühe, es herauszufinden. Man überläßt es den Dichtern, diesen sprotokollierten Firmen der Seele, erst daraus etwas Brauchbares zu machen, es zu >verarbeiten ${ }^{175}{ }^{75}$. Dieser Verarbeitungsprozeß ist es nun auch, der den "Dichter" vom »Reporter« unterscheidet. Während letzterer den Wundern des Alltagslebens gegenüber indifferent bleibt, weil seine Berichtspflicht keine Evaluierung einzelner Vorkommnisse zuläßt, zielt ersterer auf den spoetischen Kern einer Begebenheit. Allenfalls die subjektive und oft ironische Sprechhaltung verbindet den typischen Feuilletontext mit Altenbergs später Kurzprosa.

Mehr als an den redaktionellen Rubriken der Zeitung mit ihren Textsorten Nachricht, Hintergrundbericht, Kommentar, Glosse oder unterhaltender Beitrag orientierte sich Altenberg in seiner späteren Schaffensphase am gemeinhin geringgeschätzten Werbeteil mit seinen Annoncen und Produktankündigungen. ${ }^{176}$ Hier begegnete ihm nicht nur eine radikal wirkungsästhetisch zugespitzte Form von Sprache, die ohne jede künstlerische Prätention verfaßten Texte verwiesen auch stärker auf die Alltagswirklichkeit als jede noch so neutrale Meldung. Und weil die Zeichenproduktion nicht dem Aufbau einer Sphäre der Fiktion diente, sondern im Kontext lebensweltlicher Kommunikation verblieb, entstand auch keine autonome Welt des Ästhetischen, deren Berechtigung er so vehement anzweifelte. So kam es, daß sich Altenberg im Zuge seines diätetisch-hygienischen Programms konsequent der Sprache der Reklame öffnete und deren rhetorische Verfahrensweisen übernahm, ${ }^{177}$ was

174 Peter Altenberg: Die Auswahl aus meinen Büchern, S. 5.

175 Ebd., S. 6.

176 So bemerkt der Kritiker Karl Ettlinger über einen derartigen Kurzprosatext Altenbergs: "Gar den Aphorismus: ’Pasta Suin de Boutemard. Idealstes Zahnputzmittel. In Wien bei Twerdy, Apotheke, Kohlmarkt glaube ich schon einmal in etwas besserem Deutsch anderswo gelesen zu haben. Wenn ich nicht irre, im Inseratenteil der Newen Freien Presse." Karl Ettlinger: [Rez.:] Peter Altenberg: Pròdrómǒs (Berlin: S. Fischer 1906). In: Das litterarische Echo 8 (1905/06), Sp. 1046.

177 Friedell spricht denn auch zutreffend von Altenbergs »Plakatstil«; Egon Friedell: Ecce Poeta, S. 167. 
schließlich soweit ging, daß sich einzelne Abschnitte seiner Werke - am stärksten fraglos im Band Pròdrömŏs - geradezu wie eine Kompilation kommerzieller Zeitungsanzeigen ausnehmen. ${ }^{178}$ Der Autor integrierte nicht nur "Produktnamenc in seine Texte, sondern lieferte unbekümmert, weil vom Nutzen seiner Propaganda überzeugt, den »Bezugsnachweis der Ware ${ }^{179}$ gleich mit. Am deutlichsten zeigt sich der Einfluß der Reklame wohl am Beispiel des von der Firma Liebig hergestellten Fleischextraktes, der damals als Inbegriff moderner Nahrungsmitteltechnologie galt. "Die zeitgenössische Werbung « für dieses Produkt »verwendeteđ jedenfalls »Formulierungen, die jenen von Altenberg erstaunlich nahe kamen«; Barker spricht geradezu vom »kumulativen Effekt der Liebig-Werbung auf den Stil Altenbergs« ${ }^{180}$. Der österreichische Autor dürfte damit einer der ersten Textcollageure der deutschen Literaturgeschichte sein, der sich werbesprachlicher ready madess bediente. Doch damit nicht genug: Weil der Liebigsche Fleischextrakt ein geeignetes praktisches Anschauungsmodell abzugeben schien, um die modernen Möglichkeiten reduktiver Verfahrenstechnik zu studieren, wurde dieses Industrieprodukt für ihn schon früh zum ideellen Bezugspunkt seiner Ästhetik, der entscheidend dazu beitrug, eine zeitgemäBe Poetologie des Genres Prosagedicht zu entwickeln.

Indem er winhaltich wie strukturell Verfahren der Werbung, so z.B. die insistierende Wiederholung «, übernahm, mutierte »der Dichter “ freilich unversehens zum "Werbetexter ${ }^{181}$. Auch wenn dies natürlich in gewisser Weise als "Versuch ${ }^{2}$ gewertet werden kann, "neues Wortmaterial der Literatur anzueignen ${ }^{\mathbf{1 8 2}}$, und Altenbergs Verfahrensweise etwa durch ihre ausgeprägte Intertextualität zweifellos gewisse ästhetische Qualitäten aufweist, ${ }^{183}$ richtete sich dessen Bestreben letztlich doch nicht

${ }^{178}$ Altenberg dürfte einer der ersten Schriftsteller überhaupt sein, der keinerlei Berührungsängste gegenüber der Sprache der Reklame empfand und dieses Phänomen moderner Wirklichkeit vorbehaltlos in sein Werk integrierte. Seine Leistung als Gestalter von vorgefundenem lebensweltlichen Sprachmaterial und als Monteur von Realitätsausschnitten ist bis heute weitgehend ungewürdigt geblieben. Ansätze dazu finden sich bei Burkhard Spinnen: Idyllen in der Warenwelt. Peter Altenbergs Pròdromors und die Sprache der Werbung. Spinnen bemerkt an anderem Ort zu Recht: "Gegen den beginnenden Waren-Überfluß errichtete er Idyllen aus Markenproduktenc; Burkhard Spinnen: Nachwort: In: Peter Altenberg: Wiener Geschichten. Hrsg. von B. S. Frankfurt a.M.: Schöffling \& Co. 1995, S. 123 .

${ }^{179}$ Burkhard Spinnen: Idyllen in der Warenwelt. Peter Altenbergs Prödrömŏs und die Sprache der Werbung, S. 137.

180 Andrew Barker: Telegrammstil der Seele. Peter Altenberg - Eine Biographie, S. $148 f$.

181 Burkhard Spinnen: Idyllen in der Warenwelt. Peter Altenbergs Pròdrŏmŏs und die Sprache der Werbung, S. 146.

${ }^{182}$ Ebd., S. 137

${ }^{183}$ So hat Spinnen eindrucksvoll zeigen können, wie ein vermeintlich schlichter Werbetext Altenbergs auf Johann Heinrich Voß' Idylle 70. Geburtstag (1780) rekurriert; vgl ebd., S. 139-141. 
wirklich auf eine "Literarisierung « der "Markenartikel ${ }^{184}$, als viel eher darauf, die Scheinwelt Kunst durch möglichst vollständige Überführung in den Lebensvollzug nach und nach überflüssig zu machen. ${ }^{185}$ Dadurch, daß er Versatzstücke aus Zeitungsanzeigen, Werbeplakaten etc. übernahm und in seine Kurzprosa einmontierte, sollte die Grenze zwischen Kunst und Leben vollständig suspendiert werden. Ihren Ausgangspunkt nahm diese Entwicklung vom poème en prose huysmansscher Prägung, das für Altenberg während des gesamten Schaffens so etwas wie der Fluchtpunkt seiner Textproduktion blieb. Das Prosagedicht stellt in seiner Ästhetik nicht nur den Prototyp textueller Kondensierung dar, sondern fungiert zugleich auch metonymisch als Inbegriff der alltagsnahen literarischen Kurzform, die sich gewissermaßen sunterhalbı der generischen Ausdifferenzierung in distinkte Gattungen bewegt. Und so wurde ausgerechnet jenes Genre, das um 1900 das wohl am weitesten fortgeschrittene Gattungsmodell ausdifferenzierter literarischer Kommunikation darstellt, zum Einfallstor eines großangelegten ästhetischen Entdifferenzierungsprogramms, das auf eine vormoderne Ungeschiedenheit von 'Leben und Kunst abzielt.

Indern Altenberg die von ihm gepriesene künstlerische Diätetik zu einer Lebensdiätetik erweiterte und den literarischen Ausdruck seinen autobiographisch-pädagogischen Darstellungsintentionen unterordnete, geriet das Prosagedicht in den Einzugsbereich der Zweckformen und wurde zu einem textuellen Sammelbecken, in dem die unterschiedlichsten Gattungsmuster und Gestaltungstraditionen zusammenliefen. Vor allem wdas verstörend und bisweilen geradezu prätentiös Unliterarische ${ }^{186}$ der späteren Texte mit ihrer partiellen Offenheit gegenüber vorgestanzten Sprachschablonen in Verbindung mit der aggressiven Selbstinszenierung ihres Autors hatte tiefgreifende Rückwirkungen auf die Einschätzung Altenbergs durch die Zeitgenossen. ${ }^{187}$ So wie einst die lebensweltliche Existenz dieses Schriftstellers im positiven Sinne als beglaubigender Beweis für die Originalität und Einzigartigkeit seiner literarischen Hervorbringungen gegolten hatte, so wurde sie jetzt immer öfter als untrüglicher Beleg für die künstlerische Wertlosigkeit seiner vermeintlichen Gelegenheits- und Gebrauchstexte angesehen. Die sich selbst attestierte Talentlosigkeit

${ }^{184}$ Ebd., S. 145.

${ }^{185}$ Barker und Lensing sprechen denn auch zu Recht von einer wradikalen Kritik an der Institution Kunstu; Andrew Barker/Leo Lensing. Peter Altenberg: Rezept die Welt zu sehen, S. 128.

${ }^{186}$ Burkhard Spinnen: Idyllen in der Warenwelt. Peter Altenbergs Pròdrŏmǒs und die Sprache der Werbung, S. 137.

${ }^{187}$ Die bis zur Verwechslung gehende Angleichung von Literatur und Werbung wurde, wie Karl von Levetzow konstatierte, umgehend als »bezahlte Reclame" gedeutet, was Altenberg den Vorwurf der "Comuption" eintrug, Karl von Levetzow: Zwei Bücher - zwei Menschen. In: Die Gegenwart. Wochenschrift für Literatur, Kunst und öffentliches Leben 35 (1906), Bd. 69, S. 183. Die vermeintliche "Prostitution des Dichters" kompromittierte den Autor in den Augen vieler Zeitgenossen nachhaltig und entwertete auch die von ihm präferierten Textsorten; ebd. 
nährte in weiten Teilen der Öffentlichkeit den Argwohn, der 1914 (gemeinsam mit Arthur Schnitzler) immerhin für den Nobelpreis nominierte Altenberg sei nichts weiter als ein künstlerischer Dilettant, ${ }^{188}$ der eitel-kokette Selbstbespiegelung betreibe und - schlimmer noch - Literatur bedenkenlos zum Ausdrucksmittel seines exzentrischen Charakters degradiere. Infolgedessen wich die anfängliche Euphorie angesichts der unkonventionellen Kurzprosa des Neulings nach und nach einer Skepsis gegenüber der literarischen Dignität dieser Texte, die - verstärkt durch kulturkritische Vorbehalte gegenüber allen feuilletonnahen wirkenden Gestaltungsformen schließlich in offene Ablehnung überging. Und so trug Altenberg, der allererst dafür gesorgt hatte, daß das Prosagedicht in weiten Kreisen rezipiert wurde, ${ }^{189}$ zugleich ungewollt - entscheidend zur nachhaltigen Diskreditierung der Gattung bei.

${ }^{188}$ Genährt wurde dieser Argwohn nicht zuletzt durch die Emphase, mit der Friedell Altenberg zum "Typus des modemen Dichters« erklärte, dessen Modernität in seinem Dilettantismus liege: "Peter Altenberg ist nun einer von jenen wenigen gewesen, die in unserer Zeit noch immer so dichteten, als ob das Dichten gar kein Beruf wäre." Egon Friedell: Ecce Poeta, S. 13 und 133f. Da sich Friedells romantisierender Ansicht, daß in künstlerischer Hinsicht "nur Dilettantismus fruchtbar ist", die wenigsten Zeitgenossen anschließen mochten, wirkte sich auch sein ostentatives Absehen von Fragen der literarischen Form - sie komme beim wahren Künstler, dem Amateur, mebensowenig in Betracht wie etwa das Format einer photographischen Platte für die Schärfe und Richtigkeit des Lichtbildes« - negativ auf die Einschätzung von Altenbergs Texten aus; ebd., S. 133 und 135. Wie eng im übrigen der Dilettantismusbegriff im fin de siècle mit dem Phänomen des décadent verknüpft ist, hat Bauer gezeigt; vgl. Roger Bauer: Die schöne Décadence. Geschichte eines literarischen $\mathrm{Pa}$ radoxons. Frankfurt a.M.: Klostermann 2001 (= Das Abendland N.F. 28), S. 43-66.

189

Köwer bemerkt zu Recht, daß Altenbergs »Prosagedichte zu einem Grundmodell deutschsprachiger Gattungsprägung geworden sindw; Irene Köwer: Peter Altenberg als Autor der literarischen Kleinform. Untersuchungen zu seinem Werk unter gattungstypologischem Aspekt, S. 103. Vgl. in diesem Zusammenhang auch Friedells Bemerkung. "Über Nacht war dieser Name aus einem nomen proprium zu einem Gattungsbegriff geworden«; Egon Friedell: Ecce Poeta, S. 126. 